\title{
Francisco Botelho de Morais e Vasconcelos, poeta ibérico da pré- llustração e fundador da Academia dos Unidos
}

\section{Francisco Botelho de Morais e Vasconcelos, Iberian poet of Pre-IIlustration and Founder of the Academy of the United}

\section{Carlos d'Abreu}

Ministério da Educação e Ciência

PORTUGAL

abreu@usal.es

[Hipogrifo, (issn: 2328-1308), 3.2, 2015, pp. 71-109]

Recibido: 03-02-2015 / Aceptado: 27-03-2015

DOI: http://dx.doi.org/10.13035/H.2015.03.02.06

Resumo. Francisco Botelho de Morais e Vasconcelos (1670-1747), poeta português de Língua Castelhana, conviveu e ombreou com notáveis intelectuais espanhóis do seu tempo, conheceu a fama em vida, foi alçado à condição de Académico Honorário da Real Academia Española, legou-nos uma profícua e inovadora obra poética e literária e fundou na sua terra natal uma academia literária, da qual aqui procuraremos dar notícia incluindo a apresentação de um manuscrito inédito de autoria de alguns dos seus membros. Não obstante, é um autor insuficientemente conhecido no âmbito dos Estudos Ibéricos.

Palavras-chave. Francisco Botelho, bio-bibliografia, pré-Ilustração, academia literária.

Abstract. Francisco Botelho de Morais e Vasconcelos (1670-1747), a Portuguese poet of Castilian language, lived and bonded with remarkable Spanish intellectuals of his time; he reached fame while still alive, he was raised to the status of Honorary Member of the Spanish Royal Academy, and he left us a legacy which includes a prolific and ground-breaking poetic and literary work. He set up a literary academy in his own hometown, an episode we will further explore, by including an 
unpublished manuscript authored by some of its members. He is, notwithstanding, an insufficiently celebrated author within the ambit of Iberian Studies.

Keywords. Francisco Botelho, Bio-Bibliography, Pre-Illustration, Literary Academy.

\section{ANTELóaUio}

O nosso interesse pelo Poeta, Escritor e Latinista ibérico Francisco Botelho de Morais e Vasconcelos, doravante apenas Botelho, já não é novo. Une-nos o facto de ambos termos por cuna Torre de Moncorvo' e subsequentemente sermos raianos, condição que nos levou a adoptar Salamanca como a nossa capital cultural, afınal a cidade universitária que durante séculos tivemos mais próxima.

E como estamos na presença de um relevante Autor que apenas de raspão figura no cânone dos Estudos Ibéricos, fomos sobre ele reunindo informação que nos tem motivado ao seu estudo e divulgação ${ }^{2}$, não obstante pertencermos a outras áreas académicas.

Acresce a esse empenho, ser Botelho o autor português tido como o último que escreveu em castelhano ${ }^{3}$ e haver ainda criado na sua terra natal uma agremiação literária, tão ao gosto da época. Para além de ter participado, no dizer do filólogo salmantino Fernando Rodríguez de la Flor, num período particularmente fecundo da vida intelectual da cidade do Tormes - «período, que en términos conceptuales ocupa el tránsito de las mentalidades barrocas a las nuevas arquitecturas de la lógica ilustrada» ${ }^{4}$-, senão mesmo da própria e ampla cultura nacional espanhola

1. «Francisco Botelho de Morais de Vasconcelos natural desta villa he homen doito e de boas notiçias», Carvalho, Memoria das noticias..., fol. 130r. «Florecerão em Letras nesta villa o incomparavel Poeta Francisco Bottelho de Moraes Autor do poema Epico $=\mathrm{El}$ Afonso $=\mathrm{El}$ Noevo Mundo $=$ Las Cuevas de Salamanca = e as Satiras Latinas», Vasconcelos, «Torre de Moncorvo», fol. 666r. Ambos os documentos foram estudados e divulgados por Abreu, 1998.

2. As letras moncorvenses anteriores a Campos Monteiro. Francisco Botelho fundador da Academia [Literária] dos Unidos, $3^{\circ}$ Encontro de Professores de Português do Douro Superior (subordinado aos temas «Campos Monteiro» e «A língua portuguesa em S. Tomé e Príncipe»), org. Centro de Formação Intermunicipal do Douro Superior, Escola Secundária Dr. Ramiro Salgado, Torre de Moncorvo, 21 de Março de 2001; Francisco Botelho, literato e poeta ibérico (1670-1747). Apontamentos para a sua biobibliografia, V Jornadas Culturais de Balsamão, org. Convento de Balsamão (Chacim), Casa de Cultura de Freixo de Espada à Cinta, 19-22 de Setembro de 2002; Como um poeta luso de língua castelhana assistindo em Salamanca criou uma academia literária aos «discordes e desaplicados» paisanos torre-moncorvinos: Francisco Botelho de Morais e Vasconcelos (1670-1747) e a Academia dos Unidos, Congreso Internacional «Portugal y la Literatura Española del Siglo de Oro», org. GRISO-Universidad de Navarra / Centro de Literatura Portuguesa, Universidade de Coimbra, Coimbra, 3-4 de Novembro de 2014. Abreu, 1998, pp. 93-94 e 2003b; Abreu y Rivas, 2013.

3. Para esta afirmação cotejámos Garcia Peres, Catálogo razonado....

4. R. de la Flor, 2005, p. 1019. 
entre os anos vinte e trinta de Setecentos, juntamente com pelo menos Francisco José de Isla, Luis Losada e Diego de Torres Villarroel ${ }^{5}$.

E não obstante todos estes méritos, não tem merecido por parte dos investigadores mais do que meras referências, que se repetem, em repertórios e catálogos bibliográficos, sobretudo em Portugal.

No nosso referido corpus «botelhiano» consta parte da produção literária dos membros da Academia dos Unidos -é essa a designação da mencionada sociedade literária-, relativamente à actividade entre Abril e Outubro de 1731, constituída por 17 manuscritos, sobre os quais ainda nos não debruçámos de forma atenta. E, a esse conjunto documental se acrescentou agora, inesperadamente, um opúsculo manuscrito inédito da mesma academia, surgido entre velhos alfarrábios numa casa particular da vila da Torre de Moncorvo e resgatado por um nosso amigo, a cuja leitura e transcrição de imediato procedemos. Apresentá-lo-emos no final do texto precedido de uma breve introdução. Aproveitaremos ainda este artigo para acrescentar dados novos e reavaliar alguns outros, tanto mais que neste ínterim acedemos à tese que o amigo Christian Porcar - que por via de Botelho nos contactara nos inícios de 2010 através do filólogo salmantino Ángel Marcos de Dios-, havia lido na Universidade de Valência e na qual trabalhou as Satyrae latinas de Botelho.

\section{NASCIMENTO E CONTEXTO FAMILIAR}

Botelho nasceu em casa nobre na vila da Torre de Moncorvo e na sua igreja matriz foi baptizado a 6 de Agosto de $1670^{6}$. E nesse concelho duriense foi criado (e de cujo telurismo nunca foi capaz de se libertar) como ele próprio afirma em alguns versos da Satyra Secvnda?:

Cuanto quieras saber, se te concederá saberlo. Empieza. Sólo te pido
que seas breve. Me reclaman en otro lugar las órdenes de mi padre.
Después de que me vio el Duero en los nemorosos campos
hurtar a los arbustos patrios las aves canoras, después de que
me llevó en su amena corriente, cuando, niño, hendía yo
las aguas de sus fulvos vados, y plugo a las Ninfas mi nadar,
ascendí al Parnaso. En su cima sagrada mis titubeantes
huellas imprimí, como hacía tiempo deseara.
Había un venero más cristalino que las vítreas y nítidas
escarchas de la Aurora. Mirtos, flores y muchísimo laurel,
en derredor. Perfumadas frondas exhalan aromas de opobálsamo.
Resplandece una blancura impoluta. Y no agosta la ardiente
estrella Sirio, con su calor desmesurado, la sedienta orilla.

5. Rivas Calvo y Abreu, 2009. O nosso amigo Alonso Romo, 2004-2005, p. 325 -tragicamente falecido em Salamanca a 18 de Novembro de 2014-, aventa mesma a forte possibilidade de Botelho e Torres Villarroel se terem conhecido e relacionado.

6. Arosa, «Noticia de la patria» (1731), p. 285.

7. Tradução de Porcar Bataller, 2013, p. 199 (134-149). 
Si Diana se hubiese bañado en una fuente así -más hermosa que la diosa es su agua - sin peligro se habría acercado como espectador Acteón: contemplaría, perplejo, la fuente, no a la diosa.

Si Narciso se hubiese mirado en aquella linfa, viviría y preferiría esa agua a su propio rostro.

Foi filho de Francisco Botelho de Morais e de sua mulher Beatriz de Vasconcelos Saraiva; neto paterno de Paulo Botelho de Morais - militar e cavaleiro da Ordem de Cristo- e de sua mulher Isabel Coelho; neto materno de António do Amaral Amado -capitão-mór das vilas de Freixo de Numão, Horta e Touça- e de sua mulher Beatriz Saraiva de Vasconcelos; descendente pelos quatro costados de poderosas famílias da região, como refere a genealogia redigida e datada de 16 de Agosto de 1730 pelo seu conterrâneo Bernardino Arosa, pois recua sem interrupções ao sexto-avô (pela linha paterna) Luís de Matos - vassalo do rei D. Afonso V de Portugal (1438-1440) - que teve como irmão secundogénito Rui de Matos, do qual descenderam António de Matos de Noronha, bispo de Elvas e inquisidor-geral, e Sebastião de Matos, arcebispo de Braga; um sobrinho de ambos, Rui de Matos de Noronha, foi o primeiro conde de Armamar ${ }^{8}$.

Teve como irmãos varões, Alexandre Botelho de Morais, desembargador dos agravos da Casa da Suplicação, que na qualidade de filho primogénito era senhor de dois opulentos morgadios ${ }^{9}$, e Paulo Botelho de Morais, mais novo, genealogista, poeta e membro da Academia dos Unidos, nascido na vila da Torre de Moncorvo a 5 de Abril de 1677, escrevendo em 1725 a Historia da illustrissima e antiquissima familia dos Marquezes de Tavora, Senhores do Mogadouro, com uma segunda parte intitulada a Familia dos Botelhos de Moraes com a ascendencia por todos os lados, em 1730 a Arvore dos costados das pessoas nobres da villa da Torre de Moncorvo e seus contornos, com noticiosas adições aos quartos avós e, ainda, Genealogia dos Matos ${ }^{10}$.

E como irmãs, pelo menos quatro, sendo que três delas, também nascidas na vila da Torre de Moncorvo, professaram no Mosteiro de Tabosa (Sernancelhe/Viseu) - acabado de abrir portas - onde morreram e foram sepultadas: Agnes Maria de Santa Teresa (1665-1755), ingressou com 29 anos (1694), aí exerceu o cargo de abadesa e faleceu com 90 anos; Damiana Luísa de São José (1672-1758), professou aos 22 anos em companhia da irmã mais velha e lá morreu aos 84; Brites do Menino Jesus (1681-1761), ingressada com 15 anos (1696), exerceu o cargo de prioresa e aí terminou os seus dias aos 80 anos de idade ${ }^{11}$. A restante, pelo que nos informa um conterrâneo e coetâneo tanto de Botelho como de seu pai, António Veloso de Carvalho, autor da Memória relativa à vila da Torre de Moncorvo, redigida e enviada à Academia Real da História Portuguesa por solicitação do monarca que acabara de a criar, afirma que «Francisco Botelho de Morais desta villa ja faleçido escreveo huns livros genelogicos de varias familias que não deu ha empreção e

8. Arosa, «Noticia de la patria» (1740), pp. 115 e 119.

9. Vasconcelos, «Torre de Moncorvo», fol. 666; Arosa, «Noticia de la patria» (1740), p. 116.

10. Alves, 1986, vol. VII, p. 348

11. Santos, 2000, pp. 86-96 
hoje se acham em poder de seu genro Lourenço Carneiro de Vasconcelos», ou seja, o pai de Botelho tinha uma filha casada, por sinal com um personagem de quem iremos ouvi falar mais adiante ${ }^{12}$.

$\mathrm{O}$ apelido Botelho deu nome a um morgadio instituído pelo pai do nosso Escritor, com a obrigação do seu uso por parte dos administradores ${ }^{13}$, apelido que the advinha de uma sua tetravó Maria Botelho ${ }^{14}$.

Eram pois os Botelho já nos inícios do século XVII considerados como uma das importantes famílias que florecerão na Torre de Moncorvo, possuindo solar iunto a Mondim, lugar da comarqua da cidade de Lamego ${ }^{15}$. Detectámos um Sebastião Botelho, também da Torre de Moncorvo, matriculado em Artes na Universidade de Salamanca no ano de $1599^{16}$.

Com relativa frequência figuram referidos na documentação local e regional elementos desta família, detentores de cargos nas administrações públicas, na política, nas armas e na religião, havendo mesmo vários dados às letras: Manuel da Fonseca Botelho (tabelião em Torre de Moncorvo, em 1713); Doutor Agostinho Botelho (Provedor da Comarca da Torre de Moncorvo); Jerónimo Botelho de Vasconcelos (síndico do convento de S. Francisco da Torre de Moncorvo); e outros do mesmo apelido sepultados em duas campas com as armas da família Botelho, existentes nesse mesmo Convento ${ }^{17}$. Um outro Francisco Botelho, frade trinitário, foi ministro do Convento da Lousa, entre 1744 e $1747^{18}$.

Várias fazendas desta família surgem como confinantes de prédios rústicos pertencentes à igreja matriz da Torre de Moncorvo, sobretudo no tombo levantado em 1708 mas também já no de $1592^{19}$.

Não temos conhecimento que o ramo dos Botelho do nosso biografado haja possuído título nobiliárquico, todavia a casa dessa família em Felgueiras (freguesia lindante com a da Vila), que pertenceu ao miguelista José Carlos Botelho, exibe um

12. Carvalho, Memoria das noticias..., p. 130r, doc. estudado e divulgado por Abreu, 1998.

13. Machado, «Francisco Botelho de Moraes, e Vasconcellos», vol. 2, p. 119

14. Arosa, «Noticia de la patria» (1731), p. 286.

15. Gasco, 1935, p. 133. Mais concretamente Mondim da Beira, no concelho de Tarouca. $O$ apelido Botelho, de origem portuguesa, terá passado a Espanha onde um dos seus ramos no século XVI fundou um solar em Las Palmas de Gran Canaria, Arbués Villa, 1990, vol. 4, p. 1684. Os nobiliários espanhóis referem que este apelido pertence a uma importante família fundada no século XIV, por «don Martin Alonso Tello de Meneses, Ricohombre de Portugal», heróico defensor da vila de Albuquerque contra o rei de Castela D. Pedro I el cruel, empresa que Ihe valeu o epíteto de Boo Tello [o bom Tello], de cujas palavras se terá formado o apelido Botello, no dizer de García Carraffa, 1954, vol. 16, p. 170. Esta tentativa de explicação etimológica poderá eventualmente fazer algum sentido para a Língua Castelhana mas não para a Portuguesa, pelo menos na actualidade («ll» com pronúncia de «|h»). Na estratificação social da monarquia portuguesa dos séculos XII a XV, «rico-homem» corresponde ao grau mais elevado da nobreza, segundo Rodrigues, 1992. 16. Marcos, 2003, p. 93

17. José, Cronica da Santa..., pp. 318, 346 e 356-357; Abreu, 2004.

18. Abreu, 2003a, p. 24

19. Abreu, 1998; ADB, 1592; ADB, 1708. 
(modesto) brasão pétreo. E temos também informação da existência de um outro na vila de Alfândega da Fé20.

Participou Francisco Botelho de Morais (pai), na governança da edilidade torremoncorvina, como no-lo indica por exemplo o livro dos Acórdãos da Câmara Municipal da Torre de Moncorvo, na sua reunião do $1 .^{\circ}$ de Janeiro de 1700, figurando na Vereação como juiz pelo facto de ser o Vereador mais velho, ao lado de António Camelo Borges, João de Morais Cardoso e o Procurador Licenciado António Machado Sobrinho ${ }^{21}$. Foi também capitão-mór e coudel-mór da mesma Comarca ${ }^{22}$. Cultivou a genealogia, escrevendo em 1685 o Nobiliario de Familias nobres de Portugal, e particularmente da provincia de Traz-os-Montes, em 1687 o Nobiliario que contem arvores de costado das casas ilustres de Portugal, e dos principes da Europa23, e em 1689 a Origem, e progressos da grande, e antiga Caza de Villaflor, e noticia das linhas Genealogicas da sua ascendencia, e descendencia, ramos collateraes, e de suas excellencias, e perrogativas, dividido em cinco partes, e offerecido a Francisco Joze de Sampayo e Mello, e Castro terceiro do nome, e Senhor das Villas, e Honras de Villaflor, Sampayo, Mós, Chacim, Frechas, Villasboas, Parada de Pinhão, e Bemposta, Alcayde mór da Torre de Moncorvo, Senhor dos Direitos Reaes della, e dos da Villa de Freixo de Espada na Cinta24.

Sabemos que Francisco Botelho de Morais reclamou em 1704 do montante que recaiu sobre os bens da sua Casa, resultante do lançamento do imposto da décima para esse ano, porquanto no seu entender «parece haver notoria desigualdade», uma vez que da renda de 75.000 réis de Alexandre Botelho (filho mais velho) lançaram-lhe 10 tostões, da fazenda de Francisco Botelho (o nosso poeta) que rendia 70.000 réis, lançaram-Ihe 9 tostões, e da fazenda de Paulo Botelho (o outro filho) que rendia 24.000 réis, lançaram-Ihe 400 réis, enquanto que ao suplicante, tendo de renda 170.000 réis «suposto que fantasticos, pois apenas são cem mil», lançaram-Ihe de décima 12.000 réis, incluindo-se nessa verba o que devia pagar a sua mulher a quem tinham sido aplicados bens que rendiam 100.000 réis, pretendendo-se assim que o reclamante se substituísse ao cônjuge no pagamento deste imposto, tudo isso -ainda segundo o suplicante- por não terem considerado essa verba particular. O mesmo aconteceu com os bens que o reclamante possuía em Felgueiras (freguesia limítrofe da Vila), pois foram calculados em 3.900 réis, aos quais juntaram o rendimento de «huñs moinhos que chamão de cima, pertença de sua mulher e, assim se pretendesse que ela não pague a parte que the toca da dita verba: e por que não parece justo que o suplicante pague decima, e com tanto excesso, dos bens que outrem possue» ${ }^{25}$.

20. Alves, 1986, vol. 6, pp. 739 e 756; Abreu, 2002, pp. 56-57. Consta que há alguns anos atrás, segundo o memorialista nosso amigo e conterrâneo António Júlio Andrade, na demolição de uma casa antiga situada no largo adjacente a Sul da igreja matriz, apareceu uma pedra d'armas dos Botelho e que foi recolhida nos jardins da residência do advogado Manuel Ribeiro (entretanto falecido), localizada na saída Leste da Vila. 21. AHMTM, 1700.

22. Machado, «Francisco Botelho de Moraes, e Vasconcellos», vol. 2, p. 119

23. Alves, 1986, vol. 7, p. 338

24. Carvalho, Memoria das noticias..., p. 130r; Machado, «Francisco Botelho de Moraes, e Vasconcellos», vol. 2, p. 119

25. AHMTM, 1704. Esta informação faz-nos supor que os cônjuges de iure, estariam então separados de facto, administrando cada um os seus bens particulares e daí talvez a indignação do reclamante. 
Através deste documento ficamos também a saber que Botelho, ainda em vida dos pais, era já detentor de importante património na comarca da Torre de Moncorvo -e talvez em outras-, o que lhe permitiria certamente viver, mesmo no estrangeiro, dos seus rendimentos.

\subsection{Esboço genealógico}

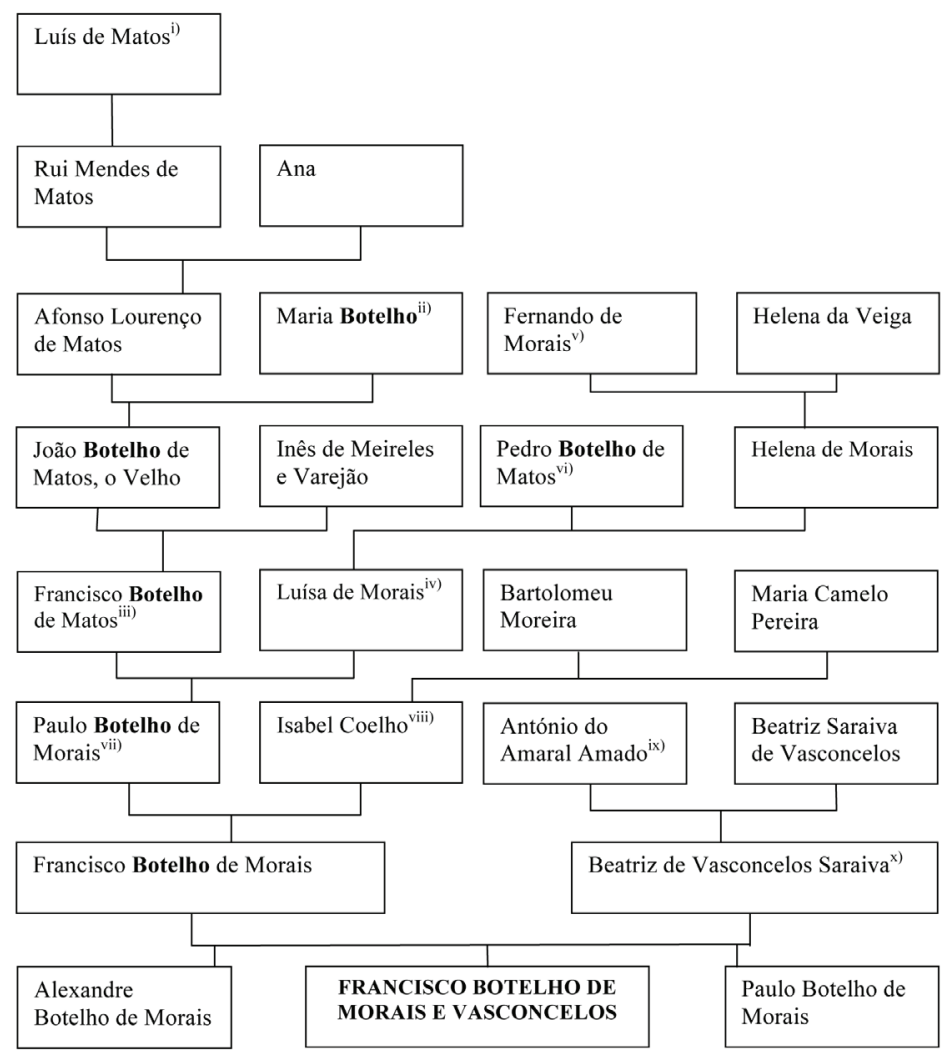

\subsubsection{Notas ao esboço genealógico ${ }^{26}$}

i) Luís de Matos (sexto avô paterno), vassalo do rei D. Afonso $V$ de Portugal.

ii) Maria Botelho (tetravó paterna), irmã de Diogo Botelho, do conselho do rei D. Manuel I.

iii) Francisco Botelho de Matos (bisavô paterno), armado cavaleiro em África, como era uso no seu tempo, pelo seu parente Francisco Botelho, capitão-general de Tânger; sepultado no convento de S. Francisco da Torre de Moncorvo ${ }^{27}$.

26. Elaboradas a partir dos informes de Arosa, «Noticia de la patria» (1731), pp. 285-289. Naturalmente que vários aspectos desta árvore genealógica de Botelho carecem de confirmação, considerando o seu tom nitidamente laudatório. E até porque se não conhece, como acima se disse, nenhum título nobiliárquico desta família, título que não teria sido difícil de obter se a proximidade com a realeza fosse efectiva como aqui se pretende dar a entender. 27. José, Cronica da Santa..., p. 357. 
iv) Luísa de Morais (bisavó paterna), prima-irmã do marido, filha de Pedro Botelho de Matos; os pais de ambos os cônjuges seriam por isso, e pelos apelidos, irmãos; era filha de Helena de Morais, por sua vez filha de Fernando de Morais, secretário de Estado de D. Filipe II no Conselho de Portugal.

v) Fernando de Morais (tetravô paterno), secretário de Estado de D. Filipe II no Conselho de Portugal; quarto neto de Estêvão Mendes de Távora, senhor da vila do Vimioso e, «descendente por varonia não interrompida de D. Ramiro II, rei de Leão».

vi) Pedro Botelho de Matos (trisavô paterno), Cavaleiro da Ordem de Santiago.

vii) Paulo Botelho de Morais (avô paterno), cavaleiro da Ordem de Cristo; militar; comandava um Terço (ou regimento) de Infantaria em direcção à Catalunha para colaborar contra a revolta que aí estalara, quando foi aclamado D. João IV («restauração da independência»-1640), regressando a Portugal e aderindo à causa portuguesa ${ }^{28}$; foi sargento-mor da comarca da Torre de Moncorvo, falecendo em 1652 e sepultado no convento de S. Francisco daquela Vila e sede da Comarca com o mesmo nome ${ }^{29}$. viii) Isabel Coelho (avó paterna), sepultada na campa do marido ${ }^{30}$.

ix) António do Amaral Amado (avô materno), capitão-mór das vilas de Freixo de Numão, Horta e Touça.

x) Beatriz de Vasconcelos Saraiva (mãe), oitava neta pelo lado paterno de Gonçalo Mendes Amado (senhor de Penela e alcaide-mór de Penedono), este por sua vez quarto neto de Pelaio Dias Amado, «Ricohombre en tiempo del Conde Don Enrìque, progenitor de nuestros Reys»; igualmente pela linha paterna, era terceira neta de Maria Peres da Guerra, descendente de Pedro da Guerra, neto do rei D. Pedro I de Portugal. Detinha o apelido de Vasconcelos por ser quarta neta de Álvaro Eanes de Tavares (descendente de Pedro Viegas de Tavares, do qual descendem também os duques de Lafões e marqueses de Arronches) e de sua mulher Maria Mendes de Vasconcelos, neta de Gonçalo Mendes de Vasconcelos, alcaide-mór de Chaves.

\section{PORTUGUÊS DE CULTURA CLÁSSICA E ALMA IBÉRICA}

Foi Botelho criado em Madrid, na companhia de um familiar que aí residia, tendo recebido uma cuidada formação que aliada à sua inteligência, cedo o haviam de tornar estimado e protegido de alguns dos grandes dessa Corte, nomeadamente o almirante Juan Tomás Enríquez de Cabrera (1647-1705), o duque de Alba Antonio Martín de Toledo, e o duque de Arcos Joaquín Ponce de León y Lencastre ${ }^{31}$, este ainda, provavelmente com ligações familiares aos Botellos de Espanha ${ }^{32}$. Numa vinda a Portugal e passando pela Torre de Moncorvo, o almirante Enríquez de Cabrera, chegou mesmo a visitar a Casa e o progenitor de Botelho ${ }^{33}$.

Esse familiar e preceptor de Botelho, Luís Botelho de Magalhães ${ }^{34}$, natural da Torre de Moncorvo, tenente de couraça do marquês de Távora, filho de Luís Botelho de Siqueira - natural de Mondim (Tarouca), Juiz dos Órfãos na Torre de Moncorvo

28. Botelho, Discurso Politico (1752), p. 3.

29. José, Cronica da Santa..., p. 357.

30. José, Cronica da Santa..., p. 357

31. Arosa, «Noticia de la patria» (1731, p. 287; 1740, p. 140); Neves, «Poetae Vita», pp. 140-141; Machado, «Francisco Botelho de Moraes, e Vasconcellos», vol. 2, p. 120; Porcar Bataller, 2013, p. 373.

32. García Carraffa, 1954, vol. 16, p. 172.

33. Arosa, «Noticia de la patria» (1740), p. 117

34. Trata-se seguramente de um parente de Botelho, pelo que se depreende da leitura do livro «Progressos Militares de Leopoldo Enrique Botelho de Magalhaens», que o refere como seu primo e sargento-mor de Dragões do exército português, que participara nas campanhas militares da «guerra de sucessão espanhola», sendo filho de Manuel Botelho de Magalhães, este capitão de infantaria e coudel superintendente da comarca da Torre de Moncorvo, Botelho, Progressos Militares (1712a), pp. 1 e 4. É provável mesmo que os dois irmãos Botelho de Magalhães fossem primos-irmãos do pai de Botelho. 
onde casara com Luísa Ferreira de Sá, herdeira do morgado da Tarrincha (Vale da Vilariça) - esse preceptor dizíamos, é referenciado como poeta e que escreveu entre outros títulos, Documentos de la Cavallaria..., em 1687, dedicado a Francisco Alfonso Pimentel, conde de Benavente e um dos «grandes de Espanha» ${ }^{35}$.

Apesar de ainda não termos encontrado o registo paroquial de baptismo de Botelho ${ }^{36} \mathrm{e}$, considerando que os irmãos não têm o apelido de Vasconcelos no seu nome, aventamos a possibilidade desse apelido ter sido adoptado posteriormente, para assim mais facilmente se poder distinguir do pai, seu homónimo ${ }^{37}$.

«Estando contente, e respeitado em Madrid, onde passey a melhor parte da minha vida, voltey a Portugal ao principio da guerra passada» ${ }^{38}$. Referia-se Botelho à «guerra de sucessão» (1703-1713), isto é, um conflito bélico de âmbito europeu desencadeada por motivos da sucessão ao trono espanhol, por morte de D. Carlos II, onde Portugal e outros países se opuseram à aliança franco-espanhola ${ }^{39}$, facto este que o obrigou a regressar a Portuga ${ }^{40}$, o que aliás já no passado fizera seu avô Paulo Botelho de Morais, em circunstâncias similares, quando marchava para a Catalunha com um Regimento de Infantaria e teve conhecimento da aclamação de D. João IV ${ }^{41}$.

Em 9 de Março de 1704 encontrava-se Botelho em Lisboa, assistindo ao desembarque de Carlos de Habsburgo que depois marchou com o rei português D. Pedro II para a raia da Guarda na tentativa de poder entrar em Castela, tendo o nosso Poeta acompanhado a expedição ${ }^{42}$. Parece que Botelho nesta questão da «guerra de sucessão», apoiou numa primeira fase a Casa de Borbón ao trono espanhol (dedicara El Nuevo Mundo a D. Filipe V), se virou depois para a causa do arquiduque Carlos de Habsburgo, encabeçada pelo almirante de Castela Juan Tomás Enriquez de Cabrera, mas da qual se terá vindo também a desviar.

Permaneceu Botelho alguns anos entre nós portugueses, tendo sido agraciado pelo rei D. João V logo no início do seu reinado (1707) com o «Hábito de Cristo» e uma pensão na Comenda de S. Pedro de Folgosinho ${ }^{43}$, da mesma Ordem, em reconheci-

35. Alves, 1986, vol. 7, p. 286

36. Não obstante as buscas levadas a cabo sobretudo nos arquivos bragançanos (distrital e diocesano). 37. Existe ainda a possibilidade de haver acrescentado ao nome esse apelido, porque em Espanha, pelo menos na actualidade, é norma o apelido da progenitora figurar no conjunto do nome, mas como segundo apelido, isto é, no fim do nome. Estaria assim Botelho mais integrado no País onde vivia. Contudo não escolheu qualquer um dos outros sobrenomes que tinha à sua disposição considerando a sua ascendência, preferiu Vasconcelos, o primeiro dos de sua mãe, decisão igualmente acorde com os hábitos espanhóis. 38. Botelho, Discurso Politico, p. 3.

39. Ferreira, 1929, p. 8.

40. Porcar Bataller, 2013, p. 27, notas XLVI y XLVII, refere um facto novo para a biografia de Botelho, informando que o nosso Poeta havia ingressado em 4 de Janeiro de 1701 como académico honorário da barcelonesa Acadèmia dels Desconfiats (1700-1703). Este informe é confirmado por Carreras y Bulbena, 1922, p. 239, assunto ao qual mais adiante se voltará.

41. Arosa, «Noticia de la patria» (1740), p. 117.

42. Porcar Bataller, 2013, pp. 21-24.

43. Alvará de atribuição do foro transcrito no Adminículo 6.1. Certamente que este presente real resultou do facto de Botelho haver convivido com D. Pedro II durante a expedição militar à raia. 
mento da criação do seu poema El Alffonso, mas cujo hábito não chegou a usar uma vez que a pensão pelo que consta nunca Ihe terá sido paga, atribuindo-se-Ihe para tal a seguinte justificação: «para ser cyreneu da cruz é preciso que me paguem»"

Desejoso de partir para conhecer, fez um giro pela Europa ${ }^{45}$, deteve-se alguns anos em Roma, cidade onde esteve hospedado no Colégio dos Padres da Congregação da Missão ${ }^{46}$. Sabemos que tendo o marquês de Abrantes Rodrigo Annes de Sá e Almeida, sido nomeado em 1711, embaixador à Cúria Romana, foi Botelho convidado para o acompanhar, viagem que lhe permitiu divulgar a sua arte nessa cidade, onde "alcançou applauzos, e estimaçoens dos maiores eruditos», tendo inclusive sido convidado pelos Árcades para seu académico, convite que declinou em virtude da Academia se encontrar por essa altura envolvida em lutas intestinas e nas quais se não quis imiscuir ${ }^{47}$.

Devido à morte de seu pai, veio Botelho de Roma a Portugal, por razões de partilhas e herança dos bens livres. Esteve na Torre de Moncorvo mas algo o enfadou e não podendo regressar a Roma como pensara, volta a Lisboa, cidade onde se encontrava em $1721^{48}$. Aí, devido a invejas e a uma qualquer maquinação de um sujeito hábil na falsificação de caligrafias e assinaturas, foi posto a mal com pessoas poderosas, situação que o levou a retirar-se para a sua terra, onde numa quinta que herdara do seu progenitor, nos arrabaldes da Vila, edificou uma casa de raiz, lá vivendo em Maio de $1730^{49}$. Estamos agora, graças à tese de Christian Porcar, investigador que estudou, introduziu, traduziu para a Língua Castelhana e comentou as Satyrae de Botelho ${ }^{50}$, mais próximos de localizar tal edifício, pois um poema latino de Botelho, «Ode Saphyca» ${ }^{51}$, foi remetido por Manuel Ferreira de Seabra para uma revista de Lisboa e nela publicado em 1816 (bem como a sua tradução por António Luís de Seabra) e, numa nota de pé-de-página, é dito que a referida composição poética foi pelo seu Autor «mandada esculpir em tres grandes pedras mettidas na parede da sua casa, na Villa da Torre de Moncorvo, junto ao Chafariz das Avelleiras, sahindo da Villa pela estrada, que conduz ao Rio Douro» ${ }^{52}$.

Nessa casa reunia em tertúlia os seus paisanos, fundando nesse mesmo ano de 1730 a Academia dos Unidos.

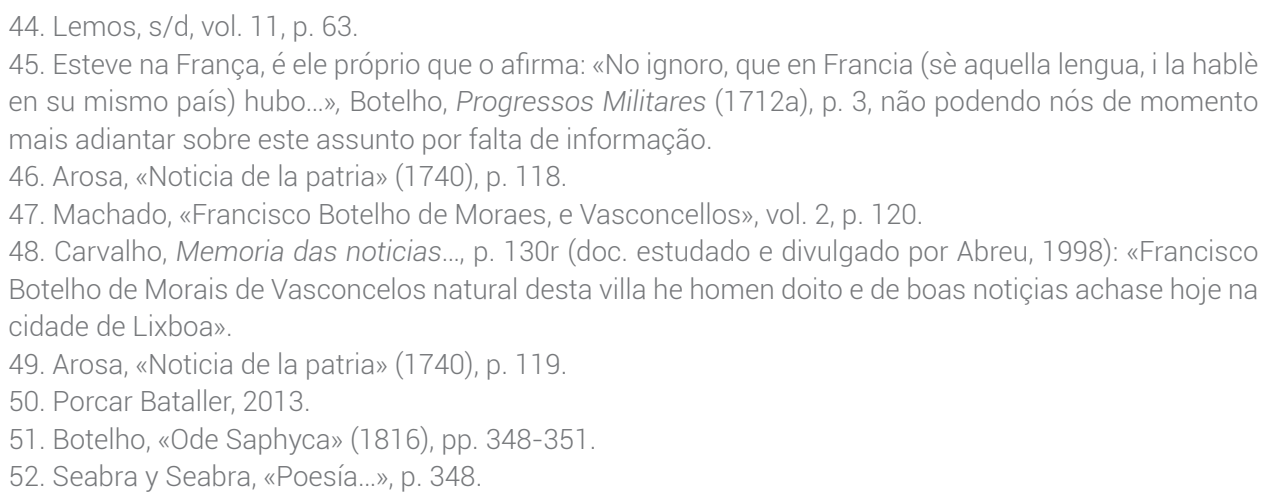


Mas nem este projecto o fixou por cá, como o próprio justifica «porque já se desvanece o rumor da guerra, quero voltar a Salamanca, sendo os principaies motivos desta resolução a minha falta de saude, e o conselho de hum Medico sabio, o qual affirma ser o clima Portuguez totalmente contrario ao meu temperamento» ${ }^{53}$, transferindo-se ainda em 1730 para Salamanca, em cuja cidade permaneceria apenas durante cinco anos, pois o corte de relações diplomáticas entre os dois países ibéricos trouxe-o pela segunda vez a Portugal e à Torre de Moncorvo, onde terá estado provavelmente até finais de 1736 ou inícios do ano seguinte porquanto, como confidencia a um conterrâneo e amigo, porque já se desvanece o rumor da guerra, quero voltar a Salamanca ${ }^{54}$, burgo onde assistia em $1744^{55}$ e aí viria a falecer três anos mais tarde ${ }^{56}$.

Morreu pois em 1747 com 77 anos, encontrando-se sepultado numa das três dezenas de igrejas paroquiais ao tempo existentes em Salamanca e, cujo registo de óbito não nos foi ainda possível encontrar nos libros de defunciones, apesar das aturadas buscas, desde há mais de uma dezena de anos a esta parte.

Conheceu Botelho o reconhecimento em Espanha da sua condição de escritor, ao ser elevado à categoria de Academico Honorario pela Real Academia Española [de la Lengua], em 7 de Janeiro de $1738^{57}$.

Recorde-se que a Real Academia Espanhola foi fundada em 1713, por iniciativa de Juan Manuel Fernández Pacheco, marquês de Villena, aprovando D. Filipe V a sua constituição em 3 de Outubro de 1714 e colocando-a sob o seu «amparo y Real Protección»58.

E assim viveu o homem de génio poético, dividido entre duas pátrias políticas e por isso discordes e até algumas vezes hostis, sina da maioria daqueles que por qualquer motivo -voluntária ou involuntariamente-, se repartem por um mundo repartido.

\section{ESCRITOR, POETA E LATINISTA}

É vasta a Obra conhecida e por nós compulsada deste excelso e insuficientemente conhecido Autor. Dela neste momento, considerando a extensão que este artigo já revela, apenas daremos conta através de uma listagem organizada por ordem cronológica de edição, com as respectivas referências bibliográficas - quando tivermos acedido directamente aos originais-, incluindo as dos repertórios, por a considerarmos uma boa base de trabalho para o estudo deste Poeta iberíaco:

- 1690, Poema en loor de S. Juan de Sahagun en la fiesta que le hizieron en su canonizacion, s/59.

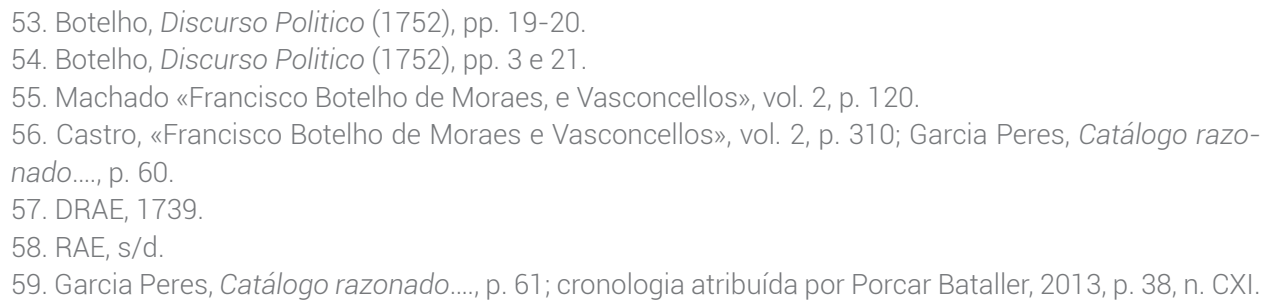


- 1696, Panegyrico Historial, Genealogico, De La Familia De Sovsa, Al Ilvsttre Señor Uasco Alfonso de Sovsa, Primer Uaron Della, Por [...], Cordoba, ed. Diego de Valverde y Leyva, y Acisclo Cortès de Ribera ${ }^{60}$.

- 1701, El Nuevo Mundo. Poema Heroyco de [...], Con Las Alegorias de Don Pedro de Castro, Cavallero Andaluz, Dedicalo Su Avtor A La Catholica Magestad de Philippo Qvinto, Avgvsto, Piadoso, Feliz Rey De Las Españas, Y Indias. Por Mano Del Ilvstrissimo Señor D. Manvel De Toledo General De Batalla En Los Exercitos De Su Magestad, \&c., Barcelona, ed. Francisco Barnola Impressor, En la Imprenta de Juan Pablo Marti61.

- 1709, Loa para la Comedia con que S. Magestad que Dios guarde festeja el día del nombre de la Reyna nuestra Señora, Lisboa, ed. Antonio Pedrozo Galrão62.

- 1711, El Alfonso del Cavallero Don [...]. Dedicado a la Magestad de Don Juan el Quinto, magnanimo, justo y siempre heroyco, Rey de Portugal, y de los Algarves. Por mano del Excelentissimo Señor Marques de Fuentes, Paris ${ }^{63}$.

- 1712b, El Alphonso del Cavallero Don [...]. Dedicado a la Magestad de Don Juan el Quinto, magnanimo, justo, y siempre heroyco, Rey de Portugal, y de los Algarves. Por mano del Excelentissimo Señor Marques de Fuentes, París, ed. Chez Estienne Michalliet ${ }^{64}$.

60. Botelho, Panegyrico Historial; Machado, «Francisco Botelho de Moraes, e Vasconcellos», p. 121; Garcia Peres, Catálogo razonado...., p. 61 (refere como editor Dionísio de Valverde); Pereira y Rodrigues, 1915, vol. 7, pp. 321-322; Palau y Dulcet, 1949, vol. 2, p. 358; Simón Díaz, 1973, vol. 6, p. 638; GEPB, s/d, vol. 34, p. 284 (apenas cita o titulo); Abreu, 2003b; R. de la Flor, 2005.

61. Botelho, El Nuevo Mundo; Silva, Dicionário..., vol. 2, pp. 358-359; Garcia Peres, Catálogo razonado...., p. 60; Pereira y Rodrigues, 1915, vol. 7, pp. 321-322; Alves, 1986, vol. 7, p. 576, citando José Augusto Tavares en A Torre de Moncorvo, de 5/10/1903; Palau y Dulcet, 1949, vol. 2, p. 358; GEPB, s/d, vol. 34, p. 284; Lemos, s/d, vol. 11, p. 63; Simón Díaz, 1973, vol. 6, p. 638; Aguilar Piñal, 1981, vol. 1 (A-B), p. 706; Hill, 2000, p. 224; R. de la Flor, 2005. Machado, «Francisco Botelho de Moraes, e Vasconcellos», vol. 2, p. 120, refere que 0 moderno addicionador da Bib. Occid. de Antonio de Leão Tom. 2 Tit. I. col. 576. Affirma que sahira impresso em Madrid. No anno de 1716. 4. Sem o ultimo complemento, e desta edição conservava hum exemplar na sua Livraria. Porcar Bataller, 2013, p. 33, n. CXIV, refere pela primeira vez uma outra edição, do mesmo ano e também de Barcelona mas na Imprenta de Gabriel Bró.

62. Machado, «Francisco Botelho de Moraes, e Vasconcellos», vol. 2, p. 121; Garcia Peres, Catálogo razonado...., p. 60

63. Pereira y Rodrigues, 1915, vol. 7, pp. 321-322; GEPB, s/d, vol. 34, p. 284; talvez a referência a esta edição, resulte de alguma confusão por parte dos autores destes repertórios, derivada quiçá do informe de Simón Díaz, 1973, vol. 6, p. 639, sobre a existência na BNP do manuscrito Observações Criticas sobre o Alfonso Poema Heroico de Frco. Botelho de Vasconcellos e Moraes. Ociosa occupação de um Ermitão no Campo de Ourique. É pois muito provável que esta edição não exista.

64. Botelho, El Alphonso del Cavallero (1712b); Machado, «Francisco Botelho de Moraes, e Vasconce\|los», vol. 2, pp. 120-121 («Esta impressão, posto que diga ser de Pariz, he de Italia»); Silva, Dicionário..., vol. 2, pp. 358-359; Lemos, s/d, vol. 11, p. 63; Palau y Dulcet, 1949, vol. 2, p. 358; Aguilar Piñal, 1981, vol. 1, p. 706; Alves, 1986, vol. 7, p. 576; Hill, 2000, p. 224; R. de la Flor, 2005; Porcar Bataller, 2013, p. 40, aponta-a como primeira edição. 
- 1716, El Alphonso Del Cavallero Don [...], Dedicado A La Magestad De don Juan $\checkmark$. Rey de Portugal, y de los Algarves. Y añadido y mejorado por su Author en esta nueva impression, Lucae, Typis Marescandoli65.

- 1731a, El Alphonso, o la Fundacion del Reyno de Portugal Asegurada y Perfecta en la Conquista de Elysia. Poema Epico del Cavallero (...); Impresso ahora la Primera vez con beneplacito de su Autor. Introducele el Mismo a la Presencia de la Serenísima Doña Maria, Princesa de Asturias, Salamanca, ed. Imprenta de Antonio Joseph Villargordo i Alcaráz ${ }^{66}$.

- 1731b, El Alphonso, o la Fundación d'el Reino de Portugal, Assegurada i Perfecta en la Conquista de Lysboa. Poema Epico d'el Caballero [...]. Dirigele Su Author A La Presencia De La Sereneissima Doña Maria, Princesa De Asturias. Con La Proteccion De La Señora Marquesa De Villalba, Salamanca, ed. Imprenta de Antonio Villargordo ${ }^{67}$.

- 1731c, El Alphonso, o la Fundación d'el Reino de Portugal, Establecida i Perfecta en la Conquista de Lisboa. D'el Caballero (...), [edição de bolso], Salamanca, ed. Imprenta de Antonio Villargordo i Alcaráz ${ }^{68}$.

- 1737, El Alphonso, o la Fundación d'el Reino de Portugal....99.

- 1712a, Progressos militares de Leopoldo Henrique Botelho de Magalhaes ${ }^{70}$.

- 1715, Tres Hymni in laude, B. Joannis á Cruce nuncupati Sanctissimo Domino Clemente XI. Pontifici Optimo Maximo. Romae per Joannem Franciscum Chracas ${ }^{71}$.

65. Botelho, El Alphonso del Cavallero (1716); Silva, Dicionário..., vol. 2, pp. 358-359; Garcia Peres, Catálogo razonado...., p. 60; Pereira y Rodrigues, 1915, vol. 7, pp. 321-322; GEPB, s/d, vol. 34, p. 284; Aguilar Piñal, 1981, vol. 1 (A-B), p. 706; R. de la Flor, 2005. Porcar Bataller, 2013, p. 40, aponta-a como segunda edição.

66. Botelho, El Alphonso (1731a); Machado, «Francisco Botelho de Moraes, e Vasconcellos», vol. 2, pp. 120-121; Silva, 1859, vol. 2, pp. 358-359; Garcia Peres, Catálogo razonado...., p. 60; Pereira y Rodrigues, 1915, vol. 7, pp. 321-322; Alves, 1986, vol. 7, p. 576; Palau y Dulcet, 1949, vol. 2, p. 358; Simón Díaz, 1973, vol. 6, p. 638; GEPB, s/d, vol. 34, p. 284; Aguilar Piñal, 1981, vol. 1, p. 706; Abreu, 2003b; Porcar Bataller, 2013, p. 40, aponta-a como terceira edição.

67. Botelho, El Alphonso (1731b); Palau y Dulcet, 1949, vol. 2, p. 358; GEPB, s/d, vol. 34, p. 284; Abreu, 2003b; R. de la Flor, 2005; Porcar Bataller, 2013, p. 40, aponta-a como quarta edição.

68. Botelho, El Alphonso (1731c); Abreu, 2003b, pp. 107-123; demos com esta edição de bolso no Archivo y Biblioteca da USAL em 2002 e desde então dela possuímos microfilmes; Porcar Bataller, 2013, não a refere.

69. Machado, «Francisco Botelho de Moraes, e Vasconcellos», vol. 2, pp. 120-121; Garcia Peres, Catálogo razonado...., p. 60; Silva, Dicionário..., vol. 2, pp. 358-359; Pereira y Rodrigues, 1915, vol. 7, pp. 321-322; Alves, 1986, vol. 7, p. 576; Palau y Dulcet, 1949, vol. 2, p. 358; Porcar Bataller, 2013, p. 41, duvida da existência desta edição.

70. Garcia Peres, Catálogo razonado...., p. 61; Porcar Bataller, 2013, p. 39, n. XCVI.

71. Título abreviado segundo Porcar Bataller, 2013, p. 41, n. CXXIV [Clementis XI, pontifici optimo maximo, Franciscus Botello de Moraes \& Vasconcellos, Christi eques, tres hymnos in laudem beati loannis a Cruce D.D.D. Romae: ex typographia Ioannis Francisci Chacras, 1715]; Machado, «Francisco Botelho de Moraes, e Vasconcellos», vol. 2, p. 121 (que abrevia o título); Porcar Bataller, 2013, p. 41, citando Aguilar Piñal, 1981, vol. 4, p. 800 (adições ao vol. 1). 
- 1716, Gratas expresiones del Cavallero D. [...] al optimo Máximo Pontifice Clemente XI. en la ocasión de los triunfos que por influencia de su Santidad tuvo la Iglesia el presente año de 1716, Lucca, por Marescandoli².

- 1732, Las cuevas de Salamanca registradas, e descriptas por el caballero [...] e dedicadas por el mismo al preclaro e mas que heroico Amadis de Gaula, Salamanca $[1732]^{73}$

- 1733, Historia de las Cuevas de Salamanca, Impressa en Hebora ${ }^{74}$.

- 1734, Historia de las Cuevas de Salamanca... Añadida, i ultimamente ajustada por el mismo, en esta segunda impression, León de Francia [Lyon] $]^{75}$.

- 1734, Historia de las Cuevas de Salamanca del Caballero [..., Chronista Mayor de los Escolares Duendes y Estantiguas, impression nueva, mejorada por su author i dedicada por el mismo a la Real Academia de Madrid, Salamanca ${ }^{76}$.

- 1737, Historia de las Cuevas de Salamanca, D'El Caballero [...]. Impression Nueva, mejorada Por Su Author; dedicada por el mismo A La Real Academia de Madrid, Salamanca, Antonio Joseph Villagordo ${ }^{77}$.

- 1740 Satyricon o Cuevas de Salamanca, Salamanca ${ }^{78}$.

- 1741, Historia de las Cuevas de Salamanca..., Salamanca, Antonio Villagordo79.

- 1838, Historia das Covas de Salamanca do Cavalleiro [...], Chronista Mór dos Estudantes, Trasgos e Feiticeiros, Abreviada e Traduzida por Joaquim Manoel d'Araujo Corrêa de Moraes, Professor d'Humanidades, Coimbra, na Imprensa da Universidade ${ }^{80}$.

- 1987, Historia de las Cuevas de Salamanca, reed. da ed. de 1737, com ortografia modernizada e introduzida por R. de la Flor, $1987^{81}$.

- 1738, Satyrae Equitis [...], academici regii Hispanae regalis academiae ab semper augusto rege Hispaniarum Matriti erectae. Cum notis et argumentis doctoris

72. Machado, «Francisco Botelho de Moraes, e Vasconcellos», vol. 2, p. 121; Garcia Peres, Catálogo razonado...., p. 60-61; Palau y Dulcet, 1949, vol. 2, p. 358; Simón Díaz, 1973, vol. 4, p. 639; Aguilar Piñal, 1981, vol. 1 (A-B), p. 706; R. de la Flor, 2005; Porcar Bataller, 2013, p. 41.

73. 0 abade de Baçal afirma que viu um exemplar desta obra, acrescentando que não possuía «ano de impressão, mas as licenças para se imprimir são de 1732», Alves, 1986, vol. 7, p. 577.

74. Palau y Dulcet, 1949, vol. 2, p. 359; Porcar Bataller, 2013, p. 42.

75. Palau y Dulcet, 1949, vol. 2, p. 359; Simón Díaz, 1973, vol. 6, p. 638; Aguilar Piñal, 1981, vol. 1, p. 706; R. de la Flor, 2005; Porcar Bataller, 2013, p. 42;

76. Machado, «Francisco Botelho de Moraes, e Vasconcellos», vol. 2, p. 121; Silva, Dicionário..., vol. 2, pp. 358-359; Garcia Peres, Catálogo razonado...., p. 60; Pereira y Rodrigues, 1915, vol. 7, p. 321; Lemos, s/d, vol. 11, p. 63; Alves, 1986, vol. 7, p. 577; GEPB, s/d, vol. 34, p. 284; Palau y Dulcet, 1949, vol. 2, p. 359; Aguilar Piñal, 1981, vol. 1, p. 707; Hill, 1994; Hill, 2000, p. 224; Porcar Bataller, 2013, p. 42.

77. Botelho, Historia de las Cuevas de Salamanca (1737); Palau y Dulcet, 1949, vol. 2, p. 359; Simón Díaz, 1973, vol. 6, p. 639; Aguilar Piñal, 1981, vol. 1, p. 707; Abreu, 2003b; R. de la Flor, 2005; Porcar Bataller, 2013, p. 42.

78. Palau y Dulcet, 1949, vol. 2, p. 359; Porcar Bataller, 2013, p. 42.

79. Simón Díaz, 1973, vol. 6, p. 639; Aguilar Piñal, 1981, vol. 1, p. 707; R. de la Flor, 2005; Porcar Bataller, 2013, p. 43. 80. Botelho, Historia das Covas (1838); Palau y Dulcet, 1949, vol. 2, p. 359; Alves, 1986, vol. 7, p. 577; Abreu, 2003b, p. 121

81. Botelho, 1987; R. de la Flor, 1987; Abreu, 2003b; Porcar Bataller, 2013, p. 41. 
domini Joannis Gonzalez de Dios, in Salamanticensi academia primarii humaniorum litterarum magistri, Salamanticae, apud Nicolaum Josephum Villargordo ${ }^{82}$;

- 1739, Satyrae $[\ldots]^{83}$.

- 1740, Satyrae $[. . .]^{84}$.

- 1741, Satyrae $[. . .]^{85}$.

- 1742 (Junho), Satyrae [...] $]^{86}$.

- 1742 (Dezembro), Satyrae [...] $]^{87}$.

- 2013, Satyrae [... $]^{88}$.

- 1743, Relação de como se ensinão no Collegio Imperial Trilingue da Universidade de Salamanca as três línguas, que Ihe dão nome Grega, Latina, e Hebrea, de que livros se servem seus doutíssimos Mestres ${ }^{89}$.

- 1743, Vida de hum Sargento mór de Dragões, com o titulo de Epitome da guerra de Filipe V, e Carlos III, em que louva muito os dous Condes de Assumar D. João, e D. Pedro de Almeida ${ }^{90}$.

- 1752, Discurso Politico, Historico e Critico, que em forma de carta escreveo a certo amigo [...], passando deste Reino para o de Hespanha, sobre alguns abusos, que notou em Portugal, Lisboa, officina de Francisco Luis Ameno, Impressor da Congregação Cameraria da Santa Igreja de Lisboa ${ }^{91}$.

$$
\text { - 1816, «Ode Saphyca» }{ }^{92} \text {. }
$$

82. Simón Díaz, 1973, vol. 6, p. 639; Aguilar Piñal, 1981, vol. 1, p. 707; R. de la Flor, 2005; Porcar Bataller, 2013, p. 43

83. Machado, «Francisco Botelho de Moraes, e Vasconcellos», vol. 2, p. 121; Palau y Dulcet, 1949, vol. 2, p. 359; Porcar Bataller, 2013, p. 43.

84. Botelho, Satyrae Equitis (1740); Abreu, 2003b (o primeiro autor a citá-la); R. de la Flor, 2005; Porcar Bataller, 2013, p. 43.

85. Botelho, Satyrae Equitis (1741); Aguilar Piñal, 1981, vol. 1, p. 707; Abreu, 2003b; R. de la Flor, 2005; Porcar Bataller, 2013, p. 44

86. Porcar Bataller, 2013, p. 44

87. Botelho, Satyrae Equitis (1742); Abreu, 2003b (o primeiro autor a citar a edição de 1742, mas sem especificar se a de Junho ou a de Dezembro, e não esclareceu porque então desconhecia que nesse ano se tivessem impresso duas edições; a carta do impressor a D. Domingo Manuel Enriquez de Anaya Sotomayor, no microfilme que da obra possuímos, está datada de 13 de Dezembro de 1742, sendo apenas este pormenor que distingue as duas edições desse ano); Porcar Bataller, 2013, p. 44.

88. Botelho, Satyrae Equitis (2013). Edição crítica e tradução para a Língua Castelhana de Porcar Bataller, 2013, pp. 113-379, a partir da ed. latina de Dez de 1742; foi o primeiro autor a recolher seis edições desta obra. 89. Machado, «Francisco Botelho de Moraes, e Vasconcellos», vol. 4, p. 128.

90. Machado, «Francisco Botelho de Moraes, e Vasconcellos», vol. 4, p. 128. Segundo Porcar Bataller, 2013 , p. 44, n. CXXXIX, «el argumento de esta obra en portugués, tal como la resume el proprio titulo, coincide plenamente con el contenido de su obra en castellano "Progressos militares..."».

91. Botelho, Discurso Politico (1752); Alves, 1986, vol. 7, p. 577; Abreu, 2003b; R. de la Flor, 2005. Porcar Battaller, 2013, p. 45, n. CXL, data a sua composição de finais de 1736 ou inícios do ano seguinte.

92. Seabra y Seabra, «Poesía...»; Simón Díaz, 1973, vol. 6, p. 639 refere como titulo em «Poesías sueltas»: Don Francisco Botello de Moraes y Vasconcelos, al assumpto del libro, y al autor. Octavas: «Preñez fecunda de la Primavera...», poema en 12 octavas incluido en los preliminares de «Descripcion historico- 


\section{A ACADEMIA DOS UNIDOS}

Como já percebemos, o carácter e a personalidade de Botelho levaram-no a relacionar-se com muitos congéneres literatos, através das agremiações literárias com que contactou ao longo das suas vivências pela Península Ibérica e fora dela, num tempo em que o «academismo» proliferava na Europa.

Uma dessas academias literárias foi a barcelonesa Academía dels Desconfíats, que o admitiu oficialmente no seu seio durante a undécima sessão, decorrida a 4 de Janeiro de 1701 [«En ellas aceptaren Alessandro Dini, napolitá y Francisco Botello de Moraes y Vasconcellos, portugués»] ${ }^{33}$.

Esta academia da capital catalã foi criada em 3 de Junho de 1700 na casa de Pablo Ignacio de Dalmases y Ros, situada na rua de Montcada, mas «El problema dinástico, la anormal situación de Barcelona y la franca adhesión de muchos de los académicos al Archiduque don Carlos, hicieron que, con la guerra de Sucesión, se extinguiera la Academia Desconfiada» em 25 de Março de 1703. Com a estabilização política os seus membros reabriram-na -com a designação apenas de Academia- e celebraram uma primeira sessão em 1 de Abril de 1729 na casa de Segismundo Comas, na rua de Tallers. E assim se manteve a inominada agremiação literária, composta essencialmente por aristocratas e eclesiásticos, até à sua refundação sob a protecção de D. Fernando VI em 27 de Janeiro de 1752 ${ }^{94}$, com a denominação de Real Academia de Buenas Letras de Barcelona e que subsiste na actualidade.

Sabemos que devido à «guerra de sucessão» (1703-1713) é obrigado a trocar Madrid por Lisboa, onde se encontra em 1704 e permanece até 1711. Transferindose depois para Roma acompanhando o seu amigo Rodrigo Anes de Sá, embaixador junto da Cúria Romana, onde permanecerá durante quatro ou cinco anos como hóspede do Colégio dos Padres da Congregação da Missão. Nessa cidade relaciona-se com a Academia da Arcádia, fundada em 1690, que o convida para seu membro, convite que declinou pelas razões já explicitadas.

Tendo que vir a Portugal resolver questões da herança por razões da morte do progenitor, acabou por se fixar durante vários anos em Lisboa, provavelmente entre 1716 e 1730, com deslocações à terra natal, Vila onde se encontrava a 16 de Agosto de $1730^{95}$ e na qual edificou uma casa de campo onde reunia os seus conterrâneos «discordes e desapplicados» através de «abundantes merendas», contando com a presença do «Senhor de Villa Flor», e com a finalidade de Ihes ser útil fundou a Academia dos Unidos, «dizendo-Ihes, que assim havião de chamar-se, e assim havião de ser», dando-lhe estatutos onde estavam consignados dias «em que devião escrever em prosa, e verso papeis eruditos, e discretos; dias em que se

panegirica de la montaña y convento religiosissimo de N. Señora de Monlora..., escrita por el R. P. Fr. Joseph Antonio De Hebrera..., Zaragoza, 1700 (referência completada por Porcar Bataller, 2013, p. 45). 93. Carreras y Bulbena, 1922, p. 239

94. Riquer, 1955, pp. 3-10.

95. Arosa, «Noticia de la patria» (1731). 
exercitassem no manejo dos cavalllos; e dias para o exercicio da Musica, e Dança», empregos que no entender do Poeta se aprendiam fora de Portugal e em Itália ensinados em colégios, conseguindo não sem dificuldade que se «renovasse a deixada imagem da equestre batalha entre duas oppostas Nações, que vulgarmente chamamos Mourisca, festejo antiquissimo»» ${ }^{96}$.

Provavelmente ainda nesse ano de 1730 vai Botelho a Salamanca supervisionar a publicação da nova edição de El Alphonso que sairia do prelo em Março de 173197, ausência durante a qual publicaram os seus paisanos na Gazeta de Lisboa que fora outro o fundador da academia literária torre-moncorvina, «ingratidão de que facilmente me esqueci, pois o mundo me sabe o nome com estimação, sem que para a conseguir me fosse necessaria a gazeta de Portugal, ou o titulo de Fundador da Academia da Torre de Moncorvo», desabafa anos mais tarde (1736 ou 1737), a um seu amigo ${ }^{98}$.

E possuía razões para assim reagir porquanto, pouco depois (1738) como sabemos, foi-lhe atribuído por aquela que viria a afirmar-se como a mais importante academia espanhola (a da Língua) a condição de académico honorário. Foi a Real Academia Española criada a 6 de Julho de 1713 por iniciativa de Juan Manuel Fernández Pacheco, duque de Escalona e marqués de Villena e seu primeiro director. É seguro que Botelho e Villena foram contertúlios na «academia» ou «tertulia» que desde finais do século XVII tinha lugar em Madrid na residência do duque de Montellano e que mais tarde se transferiu para o palácio do próprio marquês de Villena, no qual Botelho lera desde que o começara a redigir, o poema El Alphonso. Esta tertúlia esteve na origem da Real Academia Espanhola99.

Permanecerá Botelho na cidade do «Studii Salamantini» até 1735, ano em que pela segunda vez é obrigado a abandonar a Espanha, devido a um conflito diplomático que afectou as relações entre os países ibéricos. A primeira saída forçada ocorrera no início da «guerra da sucessão», como acima se viu. «E estando da mesma sorte em Salamanca, onde assisti cinco annos, deixey as minhas commodidades, e o meu gosto, quando pelos actuaes rumores, e prevenções militares, se me apresentou indecorosa a minha permanencia em Castella» ${ }^{100}$.

Neste último regresso ao torrão natal, voltou o Poeta a encontrar os seus patrícios

adormecidos de novo em outra desapplicadissima inacção. E desejando eu, que daquelle nada tornassem a sahir à luz, Ihes trouxe à memoria, que a Torre de Moncorvo se fez conhecida (entre outras boas qualidades) pelos seus genios festivos [...]. Tambem me admirou ver na Torre de Moncorvo, povoação de pouco mais de trezentos visinhos, caibão, vivão, e se accommodem sessenta e huma pessoas occupadas no ministerio judicial, ou administração da justiça [...]. Tanto diluvio de Meirinhos, Alcaides, Tabelliães, Inqueredores, etc., como pódem deixar de ser

96. Botelho, Discurso Politico (1752), p. 4

97. Porcar Bataller, 2013, p. 31.

98. Botelho, Discurso Politico (1752), p. 5.

99. Porcar Bataller, 2013, pp. 36-37, notas CV-CVI.

100. Botelho, Discurso Politico (1752), p. 3.

HIPOGRIFO, 3.2, 2015 (pp. 71-109) 
insultuosos, e de fomentar malignas sem razões, quando a ellas está vinculado o seu sustento? Para captar, e prender a benevolencia dos superiores, lhes introduzem mil enredos, com que os fazem inimigos da gente da terra. Na nossa (com vigilancia sapientissima) serve de correctivo a estes inconvenientes a próvida inteireza dos Ministros ${ }^{101}$.

Como poderemos perceber pelas palavras de Botelho, não encontrou o intelectual na Vila onde tinha raízes, uma vez mais, o ambiente adequado aos seus gostos porquanto, um ano ou ano e meio após o regresso (forçado é certo), volta definitivamente à cidade do Tormes.

A Academia dos Unidos, cujo lema Concordia insuperabilis nos lembram as palavras de Botelho, teve como primeiro presidente Francisco Inácio Botelho de Morais. Dos restantes membros conhecemos apenas o nome daqueles cujos escritos também chegaram até nós como António Carvalho Gamboa, Lourenço Carneiro de Vasconcelos (casado com uma irmã de Botelho recorde-se ${ }^{102}$ ) que foi o seu segundo presidente, Tomé de Morais da Silveira Lobo, Eustácio Carneiro de Lobão, Pedro de Siqueira Ferraz, P. Gaspar de Sá, L. do Paulo Rebelo de Carvalho, Gonçalves José de Sousa e Vasconcelos, Luís Camelo de Castro e Gaspar Leitão da Fonseca103.

Relativamente às actividades da academia torre-moncorvina várias notícias se podem coligir na Gazeta de Lisboa, a saber:

- o número de 8 de Março de 1731 informa que reunia todas as quintas-feiras em casa de Lourenço Carneiro de Vasconcelos, «dandose-Ihe principio, e fim com huma Sonata, e composição com varios instrumentos. Em cada conferencia se lem muitos discursos discretos, e elegantes, e muitas Poesias. Nesta ultima quinta feira primeiro de Março presidio nella, e fez hua erudita oração Paulo Botelho de Moraes, irmão de Francisco Botelho de Vasconcellos, autor do Poema intitulado, El Alphonso, e não menos versado na literatura» ${ }^{104}$.

- que em 12 de Abril de 1731 realizou uma conferência (a primeira «depois da suspensão em que a pozerão os exercicios devotos da Quaresma»), sendo presidente Francisco Inácio Botelho de Morais e Vasconcelos, fidalgo da Casa Real, «e por se acharem nella o Marques de Tavora, e o Conde da Ribeira grande, houve muita Poesia extemporanea em applauso destes dous Senhores. Esta Academia, tomou por empreza huma mão apertando hum molho de varas, com a letra que

101. Botelho, Discurso Politico (1752), pp. 5, 17 e 19. Estes «ministros» a que se refere o nosso Escritor, são os funcionários régios nomeados para as sedes de Concelho (juizes de fora) e para as sedes de Comarca (corregedores). Entre os últimos conheceu Torre de Moncorvo um (José António de Sá) que se virá a destacar através dos seus provimentos de correição na repressão aos abusos praticados pelo funcionalismo camarário, ainda nessa centúria (Abreu, 1998). Esse mesmo corregedor, relativamente a Torre de Moncorvo, também afirma que era cabeça de «muita justiça, ocupa-se nisso bastante gente da terra, mas sempre com pobreza vão passando a vida» (Sá, «Descripção Económica da Torre de Moncorvo», p. 271), corroborando assim a opinião de Botelho. Referiremos J. A. de Sá lá mais para o final deste trabalho a propósito da sua acção no âmbito do academismo.

102. Carvalho, Memoria das noticias.

103. BNP, 1731.

104. GL, 1731, 10, pp. 79-80. 
Alciato traz em hum dos seus Emblemas: Concordia Insuperabilis» 105; «Principiouce e acabouce com a mesma formalidade de Sonatas só teve a vantagem de no fim se rematar com hum bayle em que tambem dançou o mesmo Marqués de Tavora», segundo uma carta de um familiar do fundador, talvez mesmo o seu irmão Paulo Botelho, grande animador dessa sociedade literária ${ }^{106}$.

- a 19 de Dezembro de 1745 uma outra, na casa do académico Francisco Xavier Carneiro de Magalhães, presidida pelo secretário da Academia José Luís Carneiro de Vasconcelos, em substituição do presidente João José de Madureira Lobo. «Houve muitas Poesias em diferentes métros, e hum grande concurso de Nobreza: e acabada a conferencia, se deu principio a hum baile, que durou até depois da meya noite» ${ }^{107}$.

- celebrando uma outra em 13 de Julho de 1746108, «sendo o seu Presidente o Academico Francisco Xavier Carneiro de Magalhães, orando em métro com engenhoza idéa: e concorreu a este erudito acto toda a Nobreza da terra, e muitos religiosos doutos» ${ }^{109}$.

- participou a Academia nos festejos realizados no convento de S. Francisco da Torre de Moncorvo em 25 de Agosto de 1757, a propósito da canonização de S. Gabriel Ferreri e de Santa Helena de Pádua ${ }^{110}$.

- e envolveu-se nos festejos de acção de graças (4 e 5 de Fevereiro de 1759) determinados pela edilidade da Torre de Moncorvo [juíz de fora Francisco Andrade Machado, seu presidente, Cristóvão José de Gouveia e Vasconcelos, José Luís Carneiro de Vasconcelos, Manuel Inácio Botelho de Magalhães e Manuel da Rocha e Castro, vereadores e procurador], por se achar o rei D. José I «livre de toda a molestia» provocada pelo atentado de que fora alvo; em casa do vereador J. L. Carneiro de Vasconcelos realizou-se «huma reprezentaçam comica, a que elle mesmo fes huma introdução metrica sobre o real assunto desta festividade»; e os demais membros da agremiação «invocaram o socorro das suas Muzas, e fizeram sobre este assumpto relevantes Poesias» ${ }^{111}$.

105. GL, 1731, 18, p. 144.

106. BNP, 1731. Apresentamos a transcrição da referida carta em Adminículos 6.2.

107. GL, 1746, 3, p. 51.

108. A fazer fé num opúsculo que em 28 de Janeiro de 2004 manejámos na Livraria Sousa e Almeida (Rua da Fábrica, Porto), cujo exorbitante preço nos desviou da sua aquisição, a Academia dos Unidos tinha neste ano de 1746 como seu Presidente um espanhol, que residia em Salamanca, como Botelho (Bandera Reyero, Anuncio Feliz); ficamos no entanto com a dúvida se este José Antonio de la Bandera Reyero é o frade mercedário asturiano José Antonio Reyero de la Bandera (ou Vandera) que por essa mesma altura era professor de Matemáticas na Universidad de Salamanca.

109. GL, 1746, 31, p. 612

110. GL, 1757,41 , pp. 335-336

111. GL, 1759, 13, pp. 102-104. Esta notícia é importante porque nos informa que o vereador José Luís Carneiro de Vasconcelos era sobrinho de Botelho, e por conseguinte filho da irmã que casara com Lourenço Carneiro de Vasconcelos. Fornece-nos ainda a data da conferência onde se apresentaram os poemas relativos ao atentado real insertos no opúsculo manuscrito que divulgamos nos Adminículos. A casa deste «académico» situava-se na antiga Rua do Cubelo, que ligava o muro do lado Norte do Castelo à porta de S. Bartolomeu pelo interior da cerca medieval, requerendo o seu proprietário autorização 
No que respeita à produção literária, como se adivinha, consiste ela em orações, romances, louvores, discursos, composições poéticas várias, décimas, sonetos e até um soneto circular, tudo a panegiricar de um modo geral e como convinha, o «muyto Alto, Poderoso, Sábio, e Magnífico Rey Dom Joam Quinto, que Deus guarde: se offerece este Espherico, Acrostico, e anagramatico Soneto» ${ }^{112}$.

Ao contrário do que julgávamos até ao momento, a análise do manuscrito agora descoberto e apresentada no subítem seguinte, revela-nos ter sido relativamente longa a existência da Academia dos Unidos -criada em 1730 e ainda activa após 1770-, conhecendo durante a sua existência períodos de maior e menor actividade, e certamente também alguns de inactividade, como aliás acontece a muitas outras agremiações similares.

Da leitura do mencionado manuscrito, pertencente a essa Academia e nos Adminículos apresentado, subentende-se que (um)a sua reactivação terá ocorrido após os acontecimentos do dia 3 de Setembro de 1758 em Lisboa, pois o atentado ao rei D. José I foi o mote para o seu «renascer». E que após 1770 ainda reunia.

Mas não subsistiu seguramente para além de 1785, considerando que nesse ano se formaliza a constituição de uma outra e, num pequeno burgo como Torre de Moncorvo só mesmo por grandes rivalidades no grémio -e para isso era também necessário que a intelectualidade fosse em número maior - se justificariam duas academias. E seria expectável que o Auto de escritura ${ }^{113}$ da nova associação fizesse alguma referência à (eventual) discórdia.

Com efeito, em 15 de Junho de 1785 uma alma próxima de Botelho, mas desta feita torre-moncorvino por adopção (era bragançano e alto funcionário régio), o juiz de fora José António de Sá, posteriormente também corregedor da Comarca da Torre de Moncorvo, em reunião da Vereação por ele presidida, por inerência do cargo, e estando presentes os vereadores Manuel António de Gouveia Sá e Vasconcelos, Manuel Inácio Botelho de Magalhães e o Doutor António Manuel de Magalhães Vaz, bem como o Procurador José da Costa Pimentel, propõe a criação de uma «Academia em obséquio aos felicíssimos esponsórios dos Senhores Infantes deste Reino e do de Castela» ${ }^{114}$, a elaboração dos seus estatutos e o respectivo registo, nomeando logo nessa sessão um grupo de sócios numerários que como ele, seu presidente, seriam fundadores.

Foram eles, fundadores, José Luís Carneiro de Vasconcelos, António Xavier Carneiro, Lucas Agostinho de Gouveia Sá e Vasconcelos, Lourenço Carneiro de Vasconcelos, Frei José Bernardo, o D.r Gaspar Lopes da Silva. Foi eleito secretário o

em 1755 para junto dela edificar uma capela privativa (Sagrado Coração de Jesus), templo que já se achava construido em 1758 (ADB, 1755, p. 288; Vasconcelos, «Torre de Moncorvo», pp. 664-665) e que subsiste ao presente, ao contrário do solar que foi conhecido por Casa do Cacau.

112. BNP, 1731

113. Na sequência da nossa investigação sobre Botelho, estamos esperançados vir a encontrar no Arquivo Histórico Municipal de Torre de Moncorvo os estatutos e demais documentação desta nova academia.

114. Casamento do infante D. João, futuro príncipe do Brasil e futuro rei D. João VI, com a infanta D. ${ }^{a}$ Carlota Joaquina de Bourbón, em 8 de Maio de 1785. 
escrivão da Câmara Municipal Luís António de Oliveira Pimentel, sessão onde o vereador António Manuel de Magalhães ofereceu para as despesas iniciais $6 \$ 400$ réis de seu bolso, «para poupar este Concelho nas despesas dele, o que foi aceite por todos este obséquio» ${ }^{115}$.

Refira-se que dos três Vereadores, dois eram familiares do nosso Poeta (um Vasconcelos e um Botelho) e, dos seis sócios fundadores da novel Academia -se exceptuarmos o presidente e o escrivão da Câmara Municipal-, três eram também da família Vasconcelos.

O Vereador Licenciado, num gesto altruísta, não integrando o grupo de sócios, ofereceu uma certa quantia para as despesas iniciais da Academia, cuja criação se acabava de formalizar com o beneplácito da edilidade.

Nos Adminículos se apresentará igualmente este documento.

\subsection{O canhenho manuscrito agora descoberto}

Trata-se de um caderno cosido, com 19 fólios ao presente, numerados originalmente no canto superior direito de 2 a 19, que possui as dimensões aproximadas de $10,8 \mathrm{~cm} \times 15,5 \mathrm{~cm}^{116}$.

Faltam-Ihe pelo menos o primeiro e último fólio, o que poderá significar a perda de quatro páginas de texto, ou no mínimo de duas, considerando que o primeiro fólio aqui apresentado -que corresponde ao segundo do caderno original-, é a continuação de um poema organizado em 4 partes, de 10 versos cada um, iniciando-se com os últimos seis versos da segunda parte. E a última composição poética, o «romance» dedicado ao Cardeal Cunha, iniciado no verso do fólio 18, prossegue na frente e verso do fólio 19 e encontra-se igualmente incompleto. O opúsculo possuiria certamente uma capa (a resguardá-lo mesmo que de igual papel) e/ou folha-de-rosto, contendo eventualmente informação que nos seria de grande utilidade se tivesse chegado até nós.

Resulta este caderno de uma selecção da produção literária dos membros da referida Academia realizada ao longo de vários anos, porquanto há composições encomiásticas glosadas perfeitamente datáveis na História de Portugal, alguns dos quais factos relacionados com a família real, senão vejamos: o «terremoto de Lisboa», ocorrido a 1 de Novembro de 1755 (fol. 14r); o atentado ao rei D. José I [«celebrar a

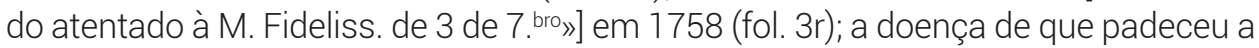
princesa do Brasil e futura Maria I [«hûa / incuravel maligna»] (fol. 11v); o casamento dessa mesma princesa [«Aos felicissimos despozorios do Se- / renis. Inf. D. P. ${ }^{\circ} \mathrm{com}$

115. AHMTM, 1785.

116. Facultado por um conterrâneo e amigo, colecionador de antiguidades e criador do Núcleo Museológico da Fotografia do Douro Superior, em Torre de Moncorvo, cuja proveniência não divulgou e que nós presumimos a tenha encontrado, ou adquirido, este ano (2014) no recheio de uma casa antiga daquela Vila. Soubemos da sua existência pelo amigo comum advogado Carlos Seixas e nesse mesmo dia o seu possuidor, professor Arnaldo Silva, nos mostrou o referido caderno manuscrito e dele amavelmente nos ofereceu cópias digitalizadas para procedermos à sua leitura, o que penhoradamente agradecemos. 
a Ser. Princeza / do Brazil D. Maria»], em 6 de Julho de 1760 (fol. 14v); e por fim um acontecimento protagonizado ou envolvendo o cardeal Cunha (fol. 18v).

Ora, o «romance» dedicado ao «Cardeal Cunha», só pode ser posterior a 1770, ano em que João Cosme da Cunha ascendeu ao cardinalato ${ }^{117}$.

Estamos pois na presença de uma (breve) «antologia» poética, em que por ora apenas identificamos os autores da «reprezentaçam comica» que a Academia realizou em honra do rei D. José nos dias 4 e 5 de Fevereiro de 1759, em casa de José Luís Carneiro de Vasconcelos, cuja copla para glosa é do próprio cicerone e os três «romances» e o «soneto» poderão pertencer a Cristóvão José de Gouveia e Vasconcelos, Manuel Inácio Botelho de Magalhães e Manuel da Rocha e Castro, porque comprovadamente presentes como atrás vimos ${ }^{118}$.

Por outro lado, traz informação nova relativamente à vida da Academia dos Unidos e sua duração no tempo, como no apartado próprio referimos. Recorde-se que a elaboração deste opúsculo resulta de uma reactivação da referida agremiação (1759), ou quiçá para comemorar esse mesmo restabelecimento.

\section{ADMINÍCULOS}

Apresentaremos neste artigo a transcrição de quatro manuscritos, como ao longo do texto fomos dando nota.

São eles o alvará de atribuição em Portugal do foro de Cavaleiro Fidalgo a Francisco Botelho (1706), uma carta de um membro da Academia dos Unidos, familiar de Francisco Botelho, talvez mesmo do irmão Paulo, e relativa à vida da academia (1731), o auto da Câmara Municipal da Torre de Moncorvo (1785) -que revela a criação de uma nova academia literária naquela Vila- e, por fim, o canhenho inédito pertencente à Academia dos Unidos e ao qual temos vindo a fazer referência.

Para o efeito, respeitámos na íntegra a ortografia, completando apenas uma ou outra palavra incompleta mas assinalando-o com [], não desdobrámos as abreviaturas, acrescentámos o sinal de interrogação entre colchetes [?] naquelas palavras que nos mereceram alguma dúvida na leitura e, mantivemos as palavras repetidas. Assinalámos ainda a mudança de fólio através do respectivo número entre [ ].

\subsection{Alvará de atribuição em Portugal do foro de Cavaleiro Fidalgo a Francisco Botelho (1706) 119}

Fran. ${ }^{\mathrm{co}}$ Botelho de Morais e Vas. ${ }^{\text {los }} \mathrm{n} .{ }^{\text {al }}$ da Torre de Mencorvo f. ${ }^{\circ}$ de Fran. ${ }^{\mathrm{co}}$ Botelho de Morais vem do I. 3 de El Rey D. João o $5 .{ }^{\circ} \mathrm{fl} 371^{120}$. 
Ouve -ng. de121 [?] p bem fazer m. ${ }^{\text {ce }}$ ao dito Fran..$^{\text {co }}$ B. ${ }^{\circ}$ de Morais e Vas. ${ }^{\text {los }}$ de o tomar por escud. ${ }^{\text {ro }}$ fidalgo com $450 .{ }^{\text {rs }}$ de moradia $p$ mês e juntam. ${ }^{\text {te }} \mathrm{o}$ acrecenta [?] logo a cavall. ro fidalgo de sua caza com 300. ${ }^{\text {rs }}$ mais em sua moradia alem do q por este tem de escud. ${ }^{\circ}$ fidalgo p. $^{\text {a }}$ q daqui em diante tenha e haja $750{ }^{r s}$ de moradia por mez de cavall. ${ }^{\text {ro }}$ fidalgo e hú alq. ${ }^{\text {re }}$ de cevada por dia paga seg. ${ }^{\text {do }}$ ordenança e he a moradia ordinar. ${ }^{\text {a }}$ e o Alvara foi feito a 20 de Fev. $^{\text {ro }}$ de 706.

\subsection{Carta de um membro da Academia dos Unidos, familiar de Francisco Bote- Iho, e relativa à vida da academia $(1731)^{122}$}

Meu Am. ${ }^{\circ}$ e m. ${ }^{\circ}$ meu S. no correyo de quatro de Abril remeti a VM hum volume del Alfonço novamente mandado impremir pello seu autor, e como foy o primeyro que chegou a Portugal me pareceu fazer a VM prezente delle, e suponho chegaria já a suas mãos.

Agora se me ofrece dar a VM conta da nossa primeira academia que se selebrou depois da festa no dia doze de Abril, que se fez mais selebre por assistirem a ella o Marqués de Tavora, e o Conde da Ribeyra, que se achavão nesta V. ${ }^{\text {a }}$ Principiouce e acabouce com a mesma formalidade de Sonatas só teve a vantagem de no fim se rematar com hum bayle em que tambem dançou o mesmo Marqués de Tavora. Foy prezidente na mesma Academia meu sobrinho Fran. ${ }^{c o}$ Ignacio Bottelho de Moraes, filho sigundo de meu p. ${ }^{\circ}$ [padrinho?] Lourenço Carn. ${ }^{\circ}$ de Vasc. ${ }^{\text {los }}$ que tambem tem o foro de seu pay. Ouve alguns versos em Louvor dos dois titulos de que remeto a VM esses como tambem algûas oraçoens e discurços que pelos nomes virá VM no conhecimento de seus autores, e em outras ocazioens hirey enviando mais algûa obras. Tenha VM sempre m. ${ }^{\circ}$ boa saude para mandar mandar. D. ${ }^{\mathrm{s}}$ g. ${ }^{\text {de }}$ a VM m. ${ }^{\mathrm{s}}$ an..$^{\mathrm{s}}$ 123

\subsection{Criação de uma (nova) academia literária em Torre de Moncorvo (1785) ${ }^{124}$}

Auto da Câmara Municipal de Torre de Moncorvo de 15 de Junho de 1785.

121. Provavelmente as abreviaturas, com alguma omissão, de «Sua Magestade».

122. BNP, 1731. Já publicada por Braga, Historia da Literatura..., pp. 57-58, que erroneamente considerou a fundação da Academia dos Unidos em 12 de Abril de 1731, o mesmo fazendo Palma-Ferreira, 1982, pp. 81-82, quando essa data corresponde ao reinício da sua actividade após a suspensão da Quaresma (GL, 1731, 18, p. 144) e como muito bem notou Porcar Bataller, 2013.

123. Esta zona do fol. foi rasgada e desapareceu e na qual figuraria o local, o dia e o mês de 1737 seguido da assinatura do remetente, remetente que é tio de Francisco Ignacio Botelho de Morais filho segundo de Lourenço Carneiro de Vasconcelos como na carta se lê. Mas este Lourenço CV, para além de primo e cunhado era também padrinho de Paulo Botelho de Morais, como Palma-Ferreira, 1982, p. 81 e Porcar Bataller, 2013, p. 32, afirmam? Ou esta afirmação resulta da notícia difundida pela Gazeta de Lisboa, como já vimos, da actividade desenvolvida pela Academia dos Unidos onde se refere que Paulo Botelho presidira a essa conferência e nela havia proferido uma oração? GL, 1731, 10, pp. 79-80. 124. AHMTM, 1785 
[113r] Anno do Nascimento de Nosso Senhor Jezus Christo de mil e setecentos e oitenta essinco annos aos quinze dias do mês de Junho do dito anno nesta Villa da Torre de Moncorvo e Cazas da Camara ahonde se juntaram em acto della o Doutor Juiz de Fora Prezidente Jose Antonio de Sá e os Veriadores actuaes Manoel Antonio de Gouvea Sa e Vasconcellos e Manoel Ignacio Botello de Magalhaez e o Procurador digo de Magalhaez e o Doutor Antonio Manoel de Magalhãez Vaz e o Procurador Jozé da Costa Pimentel e ahi por todos me foi mandado fazer este auto para nelle escreverem e determinarem o que for mais conveniente ao Real Serviço e bem comum da Republica que asignaram no fim de suas determinações, e Eu Luiz Antonio de Oliveira Pimentel o Escrevi

Nesta pello Prezidente o Doutor José António de Sá foi proposto hum plano para na forma delle se proçeder a Hua Academia em obsequio dos felecissimos Espozorios dos Sereni / [113v] dos Serenissimos Senhores Infantes deste Reino e do de Castella para se proceder na forma destes [?] Estatutos que depois de separados [?] se registaran e se açentará [?] no tempo e dia para o mesmo effecto em que todos elles Menistros convieram.

E por nam haver maiz que determinar asignaram elles Menistros Eu Luiz Antonio de Oliveira Pimentel o Escrevi

Addo intempore

E logo outro sim ouveram por bem nomear por Soçios Numerarios $p .{ }^{a}$ a referida Academia os quaes como o Doutor Juis de Fora Prezidente seram Fundadores da Academia comforme o Plano da mesma Sendo os seguintes: Jozé Luis Carneiro de

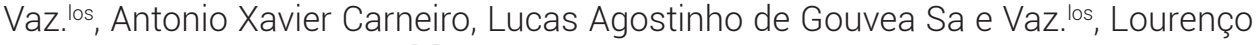
Carneiro de Vaz. ${ }^{\text {los }}$, o Rer. ${ }^{\text {do }}$ [?] Frei Jozé Bernardo, o D.' Gaspar Lopes da Sylva /

[114r]

Elegendo para Secretario da mesma Academia a mim Escrivão da Câmara e logo para este mesmo acto foi ofereçido pelo vereador o D..$^{r}$ Ant. ${ }^{\circ}$ Manoel de Mag. es seis mil e quatro centos reis . $^{\text {a }}$ poupar este Concelho nas despesas dele que the foi aceite por todos este obzequio.

E por não haver mais que determinar asignaram elles menistros e Eu Luiz Antonio de Oliveira Pimentel o escrevi.

\subsection{0 opúsculo manuscrito agora descoberto}

[1] fólio 1, perdido

[...] 
$[2 r]^{125}$

Amarei pois em secreto;

farei do peito carvão;

queimarei o coração,

por conseguir melhor bem:

tudo o mais farei: porem

peccar eu mais, isso não.

3.

Hum abismo a outro chama acende hum fogo a faisca,

quem a mais peccar se arrisca

por eterno fogo clama:

triste de quem torpe ama,

metido em tal confuzão,

se não tem no coração

mais que impressa esta Ley;

amar, sim, eu amarei,

peccar eu mais, isso não.

[2v]

A maripoza góstoza

peccando a fogo se entréga;

quem mais ao fogo se chega

mais imita a maripoza.

Fuja se quer ser ditoza,

a alma do fogo; e então

tirará por concluzão,

vendo-se em fogo tão forte:

pois há no pecado morte,

peccar eu mais, isso não.

[3r]

A Academia dos Unidos da Torre de Moncorvo, havia alguns annos estava adormecida pela auzencia de alguns Academicos: e para se celebrar a do atentado à $\mathrm{M}$. Fideliss. de 3 de 7 . bro, se avizou dando-se para glossar esta copla ${ }^{126}$

125. Contém esta página, em ambas as margens, na parte superior, apontamentos manuscritos apócrifos, executados em dois momentos, sendo que os da esquerda são numerais cardinais, em tinta azul, e parecem não ter qualquer relação com o texto, ao contrário dos 4 versos, apostos ao alto, da margem contrária: com aviso tão discreto / senti o fogo mudado / ---[?]-a pena do pecado / --[?]-- do branco for preto

126. Como atrás vimos, estas composições poéticas foram apresentadas na conferência que a Academia
Esta ilustre Academia

sem morrer, vai renascendo,

quando a Feniz só morrendo, he que renascer podia.

$1 .{ }^{a}$

1.

Em hum jardim sem cultura,

não póde haver polyantéa:

porque dormindo Amal-héa [amá-la-ei?]

nem há flor, nem hà verdûra:

mas acordando, se apûra

no jardim, que florceia,

o cuidado que dormia;

[3v]

por isso com providencia

acordou da sonolencia,

esta nossa Academia.

2.

O seu lustre bello, e forte, que Minerva a si unia, já lhe uzurpou algum dia o sono, imagem da morte: Agora porem de sorte ressuscita florecendo, que o mesmo sono vencendo mostra em suave cadencia, que de tanta sonolencia sem morrer, vai renascendo.

3.

União, que não dá fogo porque Morfêo a desune hum só vivo afecto a une, amor a reforma logo.

[4r]

seja pois o desafogo amor, vá-se entretendo, em discriçoens discorrendo já que amor he o seu dono; pois ressuscita do sono, quando a Fenis só morrendo.

realizou em 4 e 5 de Fevereiro de 1759 (GL, 1759, 13, p. 104). 
Animada pois do amor esta floresta, e reunida, já parece que tem vida, já brilha mais do que a flor:

O sonorozo vapor

Ihe tirou com bizarria

o Regio assumpto, que ouvia:

e por isso sem engano,

só de impulso soberano,

he que renascer podia.

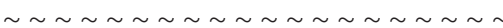

$[4 \mathrm{v}]$

Ao mesmo. Romance.

Em hum dia, senhor, a Sancta Igreja obzequioza venera ao Bispo Manço, tres infames quizerão atrevidos, e insolentes, mostrar q erão bravos. Nesta contradição, nesta ouzadia, por destino do céo, sahio frustrado, o iniquo projecto, infame, e torpe, da traidora vileza de seus braços. Mas q muito q a mão do Omnipotente, unida à mansidão de hû tal santo, dispoze-se q a perfida insolencia para si mesma fosse o seu estrago! Se a mesma ingratidão na sua esféra, como vibora vil, em seu parto, tem por morte infeliz, q a desdoura: eu mesma fui a cauza do meu dano. Desta sorte castiga o braço invicto do mais alto poder, mais soberano, a quem pérfido, ingrato, e insolente [5r]

não respeita ao culto, infringe o sácro.

E por isso dispos com alta idea,

q ficasse inviolada neste passo,

a vida inestimavel de hû Augusto,

q em trono de rigor fulmine rayos.

Quem tem visto já mais, ou q. ${ }^{\mathrm{m}}$ ouvido,

que ao solio supremo luzitano,

hûa barbara, vil, infame sombra,

se opoze-se infiel, fize-se agravo!

se em defensa de hû Rey benigno, afavel, q como a filhos ama a seus vassalos, cada hû se tem já reproduzido valerozo Dragão, fiel soldado.

Como agora em desdouro tão sensivel

estes perfidos monstruos, tão ingratos, esquecidos da gloria do seu Reino, á infamia Ihe deixão por morgado. Clamão todos, Senhor todos suplicão, e como mais fieis os Transmontanos, q desta infamia sejão pregoeiros os corpos de huns traidores, mas em quartos.

[5v]

Tudo isto vio já, tem visto,

do Austriaco, excelso, nobre braço Luzitania fiel, que agradecida, não estima já mais Brutos, e Cassios. E se ainda de seu dezignio infama hà q. ${ }^{m}$ pérfido siga o seu rasto, haja tãobem, Snr, no vosso imperio quem o peito Ihe faça em retalhos. Não tem Rey amor do povo, nem o há, tanto, quanto o Sol rodeia nesses Astros, e háde ter hû vapor atrevimento, para q tanto amor fique infamado! Hade verse ultrajada a Magestade de hû excelso Rei todo Sagrado, e cada planta, pedra, rocha, ou ferro, verdugo não será de ultrage tanto! A hû Rey todo amor para seu Reino, tão $\mathrm{am} \cdot{ }^{\text {te }}$ de paz, heroico, e grato cujas plantas Ihe beijão reverentes de todo o seu Imperio os tres Estados. [6r]

Hade haver quem se atreva, nescio, astuto, indomito, e soberbo a ultrajalo! pois morra cruelm. te $\mathrm{q}$ há lei Régia, se animada não fosse a de Palacio. E depois de hû castigo sem piedade, q nenhûa merece o desacato, louvaremos a D.s q deo justiça para dar a insultos desagravos. E rendidos nós todos, e obzequiozos renderémos as graças, por livrarnos hûa vida q he nossa, como Augusta, porq reine feliz eternos annos.

Ao mesmo. 
Qual he mais util ao Reino, se a nobreza principal que ofende, se o povo q sente a ofensa de seu Rei.

Soneto

A nobreza em hû Reino, na verdade, he generozo braço, sal prudente, que não deixa corrompa, insolente, a soberba, a maior fidelidade.

Mas se ella com mais temeridade o seu lustre corrompe excelente, toda a gloria Ihe uzurpa inclemente, em desdouro fatal da magestade.

Neste pois destempero, nesta empreza, em q firma veneno a ingratidão, só triunfa o amor, só a firmeza.

Não queiras tu, ò reino ilustre, não consentir em ti mesmo tal nobreza, q devendo ser sal, he solimão.

$\sim \sim \sim \sim \sim \sim \sim \sim \sim \sim \sim \sim \sim \sim \sim \sim \sim \sim \sim \sim$

$[7 r]$

\section{Ao mesmo}

Romance.

Rey. Sahio Apollo hua tarde Lá no seu coche a passeio, não só dispendendo luzes, mas dando às flores alentos.

Invejoza então Latona —— Marqueza. de resplendores tão bellos, Marquez. Convida à nocturna sombra a que se apreste correndo. porq os impulsos da inveja, não sofrem, nem por momentos, q brilhe em flamante signo, quem dá luz a seus defeitos. Já Semilher de cortina o cruel Saturno feito, entre densa escura noite oculta a Apollo os reflexos. Neste pavilhão escûro, [7v] retrocede Apollo, a tempo, q tres cometas o insultão, tão ingratos como féros. Vulcano pois neste lance _— Duque. sópra os folles, forja o ferro, q sempre foi impiedozo quem tem cara de ferreiro O Sagitario Ihe envia _- Marquez novo. o mais velós instrumento, com q disparada a seta fére o braço, exime opeito. Como se Apollo não fosse Briareu, com tal extremo, q de hû braço a outro braço désse ao mundo vivo alento. Ultrajado assim Apollo empunha valente o cétro, para q veja Latona os castigos do seu erro. [8r] Os outros astros fieis __Magnates da corte. rendidos a seu imperio, entre suspiros, e gostos, Ihe dedicão seus obzequios. Os suspiros porque admirão em seu principe excelso hû ultraje q inda em sonho, não houve em todo o universo. Os gostos, porque tem visto livre de hû trance funesto a quem dezejão que brilhe muitos seculos de seculos. Porem não socéga a mágoa e he tão nobre seu afecto, que por honra do seu todo, todos quizerão ser Néros. A Magestade ultrajada! profanado o seu respeito! hum Semideus ofendido! [8v] que he isto? que? Sacrilegio E não póde haver delicto, nem tão vil, nem tão horrendo; porque ao Principe das luzes todos devem ser atentos. E mais quando he tão benigno, tão afectivo, e tão terno, q a sua mesma ternura atrahe a si os afectos. Que planta, flor, ou que mirto não recebe o seu alento deste monarcha dos Astros, deste celeste luzeiro? Que estrela, astro, ou planeta, haverá neste emisferio, 
que de Apollo não receba,

lustres, favores, ou premios?

Se a sua magnificencia,

tão alta, como elle mesmo,

fertiliza, a quem fiel

[9r]

Ihe consagra rendimentos?

Pois sendo tal o delicto

de ultraje tão torpe, e feio,

que só de consideralo

estremece o pensamento.

Que será vesse offendido

tão benefico Portento,

da mais leve ingratidão,

vapor vil, e o mais soberbo?

Se tanta benignidade,

se a tão benigno conspecto,

são pouca correspondencia

todos os cultos, e incensos.

Altos pois Astros briozos — Ministros

[de justiça.

brilhe Apollo no seu Reino,

e para seus desagravos

fomentai vós os tormentos.

Porque ultraje tão ingrato,

péde castigo severo,

e será pouca influencia

todo o incendio dos incendios.

[9v]

Ao mesmo.

Romance.

Na tempestade horroroza

de hua triste noite escura

Rey. se vio Alfeu entre horrores

de hum estrepito q assusta.

O granizo era tanto,

${ }^{127}$ como a mais rapida chuva,

e só em seu triste peito

os eccos Alfeu escûta.

Mais q aflicto o nobre Alfeu,

em tragedia tão confusa

quanto respira em alento

tanto [sic] aflição lhe uzurpa.

Absorto neste conflicto

sem achar piedade algûa;

q nunca atende à piedade

127. Entre o verso imediatamente anterior e o início deste, encontra-se a palavra «balas», talvez acrescentada a posteriori, querendo o autor com ela reforçar a inclemência do granizo, em que cada pedra de gelo se assemelhava a projéctil de arma de fogo. quem do mais sagrado abuza

Cada estrondo Ihe parece

rayo, q o Erebo inculca,

[10r]

corisco atemoriza

e relampago que insulta.

Clama sem dizer palavra;

que em tão tristes amargûras

athé o silencio clama,

dá vozes a mesma injuria.

Mas já compassiva Aurora —_ Rainha.

de tão grande desventura,

convida o Sol, a que extinga

quanto a triste noite expugna.

Apréssa o passo este globo

de luzes; cessa a dispûta;

recobra Alfeu os alentos,

sólta a vóz, a arteria pulsa.

Recorre aflito a Escolapio —_ Cirurgião.

o nacar o braço inunda;

e neste acedio se admira

purpura, emfim, sobre purpura.

Canta victoria seu peito

já sua dor não é sua;

[10v]

que bastou rayasse o Sol,

para se pôr tudo em fuga.

As plantas amortecidas __ Magnates.

com tão extremosa furia,

assim como Alfeu, alentão

seu verdor, sua frescûra.

As flores, q já se vião ——Damas do paço.

no mesmo berço caducas,

animão sua fragrancia

tanto q o sol as ilustra.

Huas, e outras alegres,

ainda que a vozes mudas,

dão ao Sol seus louvores,

porq as aviva na tumba.

Mas que tem isto que ver

com a gloria que resulta

a huns coraçoens fieis,

que Alfeu a si avincûla?

Nada a isto se assemelha,

nada chega, nada avulta,

[11r]

por mais que as flores, e plantas

queirão seja a gloria sua.

Porquanto, assim como o humano

he mais nobre creatura,

assim a gloria que sente

he maior, que outra nenhûa.

Viva Alfeu eternos annos,

athé que gloriozo suba

a dar louvores eternos 
à omnipotencia summa.

Para que a sombra de Alfeu,

tão glorioza, como Augusta,

defenda de tempestades

a quem a alma the tributa.

Que somos todos aquelles,

que logramos a fortuna

de ser na fidelidade

bronze, diamante, columna.

o Assumpto era aludindo, e não

resolvendo: — qual -

[11v]

qual recebeu maior gloria na melhoria /

del Rey, se a fidelidade Portugueza q /

se considerava ofendida, se o amor de / seus vassalos.

Este Romance foi $\mathrm{m} .{ }^{\text {to }}$ gabado na Corte.

Chegando a noticia de q a Serenis. ${ }^{\text {/ Prin- }}$ ceza dos Brazis, padecendo hûa / incuravel maligna, de q a aliviou o / Sr. Jesus dos Passos, indo em procissão / da Graça ao Palacio, foi celebrado es- / te prodigio.

Romance.

Serenissima Senhora

ta! Que não sei o que digo: que infesta a Serenidade

a sombra do ar maligno.

[12r]

Princeza Augusta; isto sim agora já sei que atino,

que não perde o Principado

o Sol no Eclipse mais vivo.

Cá neste Certão inculto,

aonde o brilhante licio

se rebuça Transmontano,

porq reine o Brigantino.

Se ouvio hua voz, Senhora,

tão triste q em meu estillo,

mostrou q ereis vos o Ecco

sendo nós todos Narcizos.

Enferma a nossa Princeza!

a flor do luzo em deliquio?

como assim? clamava anciozo

todo o nobre peito aflicto.

He possivel se atrevesse com tão grande dezatino,

hûa vil enfermidade

a hû sólio tão subido?

[12v]

Quem já mais vio athéqui,

que no jardim mais florido

fize-se 0 ar pestilente

de hua Angelica, Jacinto?

Que lapidario tão destro

há no mundo ou tem havido,

que do mais nobre diamante

fize-se algum Amethisto?

Que nuvem escûra, e densa,

deu já voo tão altivo,

que uzurpe ao Sol os rayos,

por mais q encubra seus vizos?

Pois como assim tem hû mal

em funesto parossismo,

hûa flor, aquem o Sol

envéja, em seu mesmo giro?

Como atrevido e soberbo,

háde ser tão prezumido,

que só por ser insolente

transforme em falso, o q he fino?

[13r]

Senão há na medicina,

quem vença o fatal dezignio

de tanta temeridade,

de arrojo tão atrevido.

Se não há na Relação,

para tão atróz delito,

Ley, q os peitos desagrave,

verdugo, que dê castigo.

Todos nós recorreremos

humildes, fieis, rendido,

ao trono da piedade,

ao tribunal do Empireo.

Serão nossas expressoens,

holocaustos, sacrificios;

porque alcanção os incensos,

o que não consegue o Nitro.

Mas a tão triste noticia,

outra nos deo compassivo

quem, por creditos de amante,

vos livrou deste conflicto.

[13v]

Em novo Palacio entrou,

quem Senhora? Jesu Christo,

com a cruz com que desceu

de outro, como em ludibrio.

E logo ficou frustrado

de tanta maligna o vicio:

que nunca mancha o humano,

a quem socorre o Divino.

Que amante, q por dar vida, 
deo a vida em sacrificio, basta q entre em Palacio para logo dar alivio. A favor tão grande sublimado, a tão grande beneficio, cante louvores a Corte, cantemos todos os hymnos. E vós, discreta Princeza, com respeito agradecido, cantai glorias ao excelso, com louvores infinitos.

[14r]

Ao terremoto de Lisboa. Soneto.

Já Lisboa te vi Princeza augusta de Asia, America, Africa, e Europa, mais brilhante, q a flor, em verde cópa no jardim de Amalthéa, e mais robusta: Mas agora te vejo (òh quanto custa esta vista, a q. ${ }^{\mathrm{m}}$ vio teu vento em popa!) horroroza campina, em q não tópa a vista mais, q triste pira adusta: Bem tomaste da flor a natureza, pois na mesma fragrancia, oh q mágoa! mais q murcha ficou tua beleza. A impulsos do ardor q o marte frágoa, me parece q es já não Princeza, Narcizo em fogo, salamandra em ágoa. [14v]

Aos felicissimos despozorios do Serenis. Inf. D. P. ${ }^{\circ} \mathrm{com}$ a Ser. Princeza do Brazil D. Maria.

Romance

Cinco letras em Pedro se divizão Em Maria tambem cinco se achão, cinco folhas se contam na Açucena cinco tem o Jasmim todas nevadas. Cinco quinas adornão a corôa, q este reino domina; cujas armas são terror formidavel, alto assombro, p. ${ }^{a}$ America, Asia, Europa, e Africa.
Não sem misterio vinculou agóra o supremo esplendor, sabio monarcha, o Jasmim, e Açucena, no consorcio, q festivo se aplaude nesta estancia. Porque em candida, pura symetria, dos afectos vitaes, q amor enlaça a Açucena ao Jasmim désse o alento, o Jasmim à açucena toda a alma. [15r]

Em sympatica, doce suavidade, com as quinas assim multiplicadas, cada letra gozásse mil troféos, cada troféo milhares de bonanças. Ditozo Portugal, pois te assegûra tua sorte feliz, tua fragrancia a candura de Pedro, e de Maria como flores augustas, q te esmaltão. Tua a gloria será, tua a ventura os aplauzos aviva, glorias canta; porq aonde a ventura predomina, o mais tenue se alenta, não desmaia. Não temas opressão, ou decadencia, pois se Jozé a vida te dilata extirpando gloriozo a hipocrezia, que teu peito fiel infecionava. No candido Jasmim, alva Açucena, depozita o vigor, que te afiança esta gloria, que gozas; porq sempre a tua gloria seja requintada. $[15 \mathrm{v}]$

Nunca te assustem as ruidozas ondas q ao mar da republica destragão; porq tem seu faról discreto, e douto - secretar... $q$ as sossegue fiel com eficacia. Quantos rubís em si continha aquella, q a natureza adorna com grinalda, outros zofiros tantos, ter queria o famoso Darío, e não achava. E se tantos não há em tua esféra, q fieis fortifiquem gloria tanta, nem por isso serás menos ditozo, pois hû zofiro tens, esse te basta. Com reciproco amor, suave afecto, sendo Augusto a ternura, Livia a graça, tudo gloria será, tudo socêgo, neste Imperio feliz da Luzitania. Seja pois nos Augustos perduravel o sublime candor desta aliança q enlaçado o Jasmim com a Açucena, ramilhete produz, nardino de Austria. [16r] Porque a sábia, eterna Providencia, aos rógos humildes sempre grata, de tão linda aréola; tão florida, o fasciculo géra, a flor inflama. 
Aviva a tua fé, teu peito alenta, q esta dita q logras, outra alcança: q a promessa real do Omnipotente, aonde a fé se aviva nunca falta. Nesta Torre se forme Epitalamio, em sonóras cadencias delicadas; porq dita tão grande, e tão sublime, se eterniza no métro, se a decanta. As Driades, Medriades, Napéas, em festivo louvor, formem as danças; e nesta aurea, discreta Academia os conceitos publiquem glorias tantas.

Dizem fôra este Romance muy / celebrado em Palacio, mas o premio / foi o trabalho.

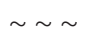

[16v]

$$
\begin{aligned}
& \text { A sua A. Serenissima } \\
& \text { copla. }
\end{aligned}
$$

A Torre inda que distante dá salvos a Sua Alteza, sobre as ameyas da fama, com os clarins da agudeza.

$$
1
$$

Ventura como a de Braga outra Curia não a logra; se ella não fosse sogra nunca viria a ser praga. quem tão belo adorno traga não há hoje, que brilhante a ilustra hum Infante; mas como se ver tão ditoza, não he menos venturoza a Torre, indaque distante.

Braga toda em luminarias a louvar seu bem recorre; porem Minerva na Torre [17r] 0 aplaude em cançoens varias, nem por isso são contrarias glorias de tanta grandeza tudo são luzes; fineza he tudo; q amor Ihe traga, quando a Torre, como Braga, dá salvas a sua Alteza.

$$
3
$$

A Torre não sendo magra, tem aparencias de Antão, se hum corvo lhe nega o pão, hum Infante lho conságra vendo-se assim menos ágra em louvores se derrama; e he tão vigoroza a chama do grande afecto, que indica, que suas glorias publica, sobre as ameyas da fama.

Alto pois, ilustre Torre, [17v] não cesses na melodia; pois hû Infante te invía o que o corvo não socorre, Em consonancias, discorre teus apluzos, com presteza; canta louvor a sua Alteza, em melodica caterva, com as plumas de Minerva, com os clarins da agudeza.

Soneto.

Já na curia Primás não há incuria, já he tudo vigor de luz febéa já não campa Morfeu, florece Astréa já se ve na exacção frustrada injuria: Mas quem fez tão mudavel hua curia, que era toda primor de alta idéa? a chegada feliz de quem campéa como filho do Sol, Tonante furia: Como póde ser isto, se a memoria de hum tão benigno Sol, ainda conta q anexava ao cetro a bizarria?

[18r] pois não ves que vincûla maior gloria, quem benevolo toma à sua conta, q a justiça dê lustre à Primazia.

Soneto.

Não te admires pois, Braga não te assustes, 
que se o raio do Sol he todo activo, quazi sempre tambem he compassivo onde acha a razão livre de embustes: justo he te glorees, e te ajustes aos altos designios de hû Archivo, das ciencias, que o Sol deixou ao vivo, p. ${ }^{a}$ teu grande lustre, em q lhe custes. Ditoza tu, que logras a ventura de ter por teu Snr. hû astro Augusto, q em balança de Astréa o justo peze. não he só dita tua, com ternura mais que ufana celébra Heroe tão justo a nobreza feliz desta Dioceze. [18v]

Ao Eminentissimo Snr Cardeal Cunha / no sentimento com q se hia contami- / nando a escandaloza doutrina de se manifestar o complice, falando com a Igreja Catholica.

Romance.

Como tão triste, como tão aflicta, sendo em tudo perfeita e imaculada; suspirando gemes, ò querida espoza, do mais excelso inclito monarcha? Se a ruga sentes, q a tartareo assopro em teu puro candor imprimir trata, não te afadigues não, q o Sol q adóras, brandindo rayos, inda vibra chamas. Teus suspiros sossega, teus lamentos, que espoza tão formoza não desmaia, quando Ihe impoem ruga tão aerea, e tosca, que p. ${ }^{a}$ a reprimir a cunha basta. Esta Cunha, que brilhante rayo de teu candido ser, tanto se abraza, [19r]

que estampada no pérfido designio rebate com fervor, quanto elle estampa. Por sua conta deixa o desafogo de seu pranto sensivel, que he disgraça lastime o sentimento, a quem tão pura ostenta seu vigor sem ruga, ou mancha. Naquele peito heroico, filho amante dessa tua candura, em fim descansa; q não consentirá teus desalentos, quem te sabe adorar com vida, e alma. No incendio de amor se acende activa esta Cunha prudente, e mais q sábia. Socéga, pois, socéga; que o seu fogo vibrando chispas, o vapor aclara. Dos Fraticelos a maldita idea, não viste já punida, já queimada? dos Donatos não viste o tosco emprego desfeito em cinzas, submergido em ágoas Pois quem soube queimar os Fraticelos, Donatos, e outros tais, temes não saiba [19v] destruir a idea, q os imita, rechaçar o designio, que os compára? Dilata o coração, modéra o pranto, rompe o véo a dor, o luto rasga: q não chora hua may tendo hû tal filho, porq outros a queirão ver madrasta. Confia no valor, na honra, e brio deste filho, q amante te idolátra, q aonde reina amor, ou resplandece, não he sombra q dure, e tudo acaba. E quando não fosse tão briozo o pulso, com q esgrime valente a tua espada, ainda Portugal tem fé sincera com q saiba evadir a tua mágoa. Se na ley escripta, o adultério com pedras se oprimia, e castigava, para quem como ingrato te adultéra as pedras troca em fogo a ley da graça E quanto aos mais filhos, tem por certo, que durando algum tempo a pertinacia [20] $[\ldots]$ [fólio inexistente por se ter perdido] 


\section{BIBLIOGRAFIA}

Abreu, Carlos d', Torre de Moncorvo. Percursos e materialidades medievais e modernos, Dissertação de Mestrado em Arqueologia, Faculdade de Letras, Universidade do Porto, 1998.

Abreu, Carlos d', «O Património Cultural do Sul do Distrito de Bragança Segundo o Abade de Baçal - tentativa de elaboração de índices temáticos às Memórias Arqueológico-Históricas», Brigantia. Revista de Cultura, 22.1-2, 2002, pp. 9-96.

Abreu, Carlos d', «Para a História do antigo Convento Trinitário e culto à Senhora dos Remédios na Paróquia de S. Lourenço da Lousa», Côavisão - Cultura e Ciência, 5, 2003a, pp. 43-57.

Abreu, Carlos d', «Francisco Botelho Poeta Ibérico do Século das Luzes», Praça Ve-

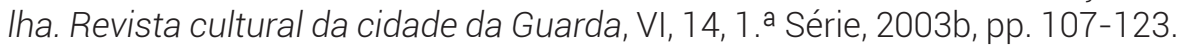

Abreu, Carlos d', «A Construção do Convento de S. Francisco no Contexto da Evolução Urbanística da Vila de Torre de Moncorvo», Côavisão - Cultura e Ciência, 6, 2004, pp. 15-33.

Abreu, Carlos d' y Emilio Rivas Calvo, «O poeta torre-moncorvino Francisco Botelho e o tema da Cueva de Salamanca», Revista do Colégio Campos Monteiro. Espaço de cultura e memória, s/n. [7], 2013, pp. 63-83.

ADB (Arquivo Distrital de Braga), Tombo das propriedades dos beneficiados desta igreja da villa da Torre, Gaveta das Cartas, doc. 4, 6 de Junho de 1592, fols. 267v-270r [treslado do séc. 18].

ADB (Arquivo Distrital de Braga), Tombo das propriedades da igreja de Santa Maria da Torre de Moncorvo, Registo Geral, Livro 65, 27 de Junho de 1708, fols. 2r-6v.

ADB (Arquivo Distrital de Braga), Registo de Provisão de Licença para o Suplicante edeficar de novo a Capella de que trata [Santíssimo Coração de Jesus], Registo Geral, Livro 122, 18 de Agosto de 1755, fols. 286v-290v.

Aguilar Piñal, Francisco, «Botello de Moraes y Vasconcellos (Francisco)», en Bibliografía de autores Españoles del Siglo XVIII, Madrid, Consejo Superior de Investigaciones Científicas/Instituto «Miguel de Cervantes», 1981, vol. 1 (A-B), pp. 705-707.

AHMTM (Arquivo Histórico Municipal de Torre de Moncorvo), «Acta n. ${ }^{\circ}$ 1: ordenação dos vereadores para esse ano», en Livro dos Assentos [ou dos Acórdãos], 1 de Janeiro de 1700, fols. 1-2.

AHMTM (Arquivo Histórico Municipal de Torre de Moncorvo), Livro da Décima, doc. solto de 4 pp., 15-18/27 de Setembro de 1704.

AHMTM (Arquivo Histórico Municipal de Torre de Moncorvo), Auto de Câmara de 15 de Junho de 1785, Livro dos Acórdãos e Determinações (1784-1786), fols. $113 r / 113 v / 114 r$. 
ANTT (Arquivo Nacional da Torre do Tombo), Alvará. Foro de Cavaleiro Fidalgo a Francisco Botelho de Moraes e Vasconcelos, Registo Geral de Mercês, Mercês de D. Pedro II, LIV. 17, 20/2/1706, fol. 6v.

Alonso Romo, Eduardo Javier, «Torres Villarroel y Portugal», en Aula Ibérica, Actas de los Congresos de Évora y Salamanca (2006-2007), ed. Ángel Marcos de Dios, Salamanca, Ediciones Universidad de Salamanca, 2007, pp. 323-334.

Alves, Francisco Manuel, Memórias Arqueologico-Historicas do Distrito de Bragança. Os Notáveis, vol. VII, Bragança, Museu do Abade de Baçal, 1986, 3. ${ }^{a}$ ed.

Arbués Villa, Javier, «Botello», en Gran Enciclopedia de España, dir. Javier Arbués Villa, Zaragoza, Enciclopedia de España, 1990, vol. 4, p.1684.

Arosa, Bernardino Pereira de, «Noticia de la patria, linage y principales successos del Poeta. Escrita por [...], Cavallero de la Orden de Christo, y natural, y morador de la Torre de Moncorvo», en El Alphonso, o la Fundacion del Reyno de Portugal Asegurada y Perfecta en la Conquista de Elysia. Poema Epico del Cavallero Francisco Botello de Moráes y Vasconcélos; Impresso ahora la Primera vez con beneplacito de su Autor. Introdúcele el Mismo a la Presencia de la Serenísima Doña Maria, Princesa de Asturias, Salamanca, Imprenta de Antonio Joseph Villargordo i Alcaráz, 1731 [Botelho 1731a], pp. 285-288.

Arosa, Bernardino Pereira de, «Noticia de la patria, linage y principales successos del Poeta. Escrita por [...], Cavallero de la Orden de Christo, y natural, y morador de la Torre de Moncorvo», en Satyrae Equitis Domini Francisci Botello de Moraes et Vasconcellos, Academici Regii Hispanae Regalis Academiae ab semper Augusto Rege Hispaniarum Matriti erectae. Cum Notis et Argumentis Doctoris Domini Joannis Gonzalez de Dios, In Salamanticensi Academia Primarii Humaniorum Literatum Magistri, Salmanticae, Apud Nicolaum Josephum Villargordo, 1740, pp. 114-119.

Bandera Reyero, José Antonio de la, Anuncio Feliz de el nacimento de un principe deseado en el de una Princesa aplaudido, Sermon gratulatorio de la Princesa de el cielo Maria, en su festiva entrada à las luces de la Gloria, por la dichosa entrada de la quarta Princesa, Infanta de Portugal, a las luces de la vida: por [...] Canonigo Commendador Presbytero, del Orden de Sancti Spiritus, Lector publico que fue, de Artes, y Theologia, Regente de ambos Estudios, Socio de universal erudicion de la Real Sociedad, Medico-Chymica de Sevilla, y Presidente de la famosa Academia de los Unidos de dicha Villa de Moncorvo. En Salamanca, por Antonio Villagordo, año de 1746.

BNP (Biblioteca Nacional de Portugal), Academia dos Unidos da vila de Torre de Moncorvo, Secção de Reservados, Códice 126 (Colecção Pombalina), 1731 (Miscellanea litteraria - «Colecção de poesias e prosas de differentes auctores que ajuntou a curiosidade de José Freire de Monterroyo Mascarenhas, Lisboa, 1726-1748»).

Botelho de Moraes e Vasconcellos, Francisco, Panegyrico Historial, Genealogico, De La Familia De Sovsa, Al Ilvsttre Señor Uasco Alfonso de Sovsa, Primer Ua- 
ron Della, Por [...], Cordoba, Diego de Valverde y Leyva, y Acisclo Cortès de Ribera, 1696.

Botelho de Moraes e Vasconcellos, Francisco, El Nuevo Mundo. Poema Heroyco de [...], Con Las Alegorias de Don Pedro de Castro, Cavallero Andaluz, Dedicalo Su Avtor A La Catholica Magestad de Philippo Qvinto, Avgvsto, Piadoso, Feliz Rey De Las Españas, Y Indias. Por Mano Del Ilvstrissimo Señor D. Manvel De Toledo General De Batalla En Los Exercitos De Su Magestad, \&c., Barcelona, ed. Francisco Barnola Impressor, En la Imprenta de Ivan Pablo Marti, 1701.

Botelho de Moraes e Vasconcellos, Francisco, Progressos Militares de Leopoldo Enrique Botelho de Magalhaens; escrito por su primo el Caballero [...], s/l, s/d [1712a (segundo Porcar, 2013, p. 39, n. CXVI)].

Botelho de Moraes e Vasconcellos, Francisco, El Alphonso del Cavallero Don [...]. Dedicado a la Magestad de Don Juan el Quinto, magnanimo, justo, y siempre heroyco, Rey de Portugal, y de los Algarves. Por mano del Excelentissimo Señor Marques de Fuentes, París, Chez Estienne Michalliet, 1712b.

Botelho de Moraes e Vasconcellos, Francisco, El Alphonso Del Cavallero Don [...], Dedicado A La Magestad De don Juan V. Rey de Portugal, y de los Algarves. $Y$ añadido y mejorado por su Author en esta nueva impression, Lucae, Typis Marescandoli, 1716.

Botelho de Moraes e Vasconcellos, Francisco, El Alphonso, o la Fundacion del Reyno de Portugal Asegurada y Perfecta en la Conquista de Elysia. Poema Epico del Cavallero [...]; Impresso ahora la Primera vez con beneplacito de su Autor. Introducele el Mismo a la Presencia de la Serenísima Doña Maria, Princesa de Asturias, Salamanca, Imprenta de Antonio Joseph Villargordo i Alcaráz, 1731a.

Botelho de Moraes e Vasconcellos, Francisco, El Alphonso, o la Fundación d'el Reino de Portugal, Assegurada i Perfecta en la Conquista de Lysboa. Poema Epico d'el Caballero [...]. Dirigele Su Author A La Presencia De La Sereneissima Doña Maria, Princesa De Asturias. Con La Proteccion De La Señora Marquesa De Villalba, Salamanca, Imprenta de Antonio Villargordo, 1731b.

Botelho de Moraes e Vasconcellos, Francisco, El Alphonso, o la Fundación d'el Reino de Portugal, Establecida i Perfecta en la Conquista de Lisboa. D'el Caballero..., [edição de bolso], Salamanca, Imprenta de Antonio Villargordo i Alcaráz, 1731c.

Botelho de Moraes e Vasconcellos, Francisco, Historia de las Cuevas de Salamanca, d'el Caballero Francisco Botello de Moráes i Vasconcélos. Impresión Nueva, Mejorada por su Autor, i Dedicada por el Mismo a Real Academia de Madrid, Salamanca, ed. Antonio Joseph Villargordo, 1737.

Botelho de Moraes e Vasconcellos, Francisco, Satyrae Equitis Domini Francisci Botello de Moraes et Vasconcellos, Academici Regii Hispanae Regalis Academiae ab semper Augusto Rege Hispaniarum Matriti erectae. Cum Notis et Argumentis Doctoris Domini Joannis Gonzalez de Dios, In Salamanticensi 
Academia Primarii Humaniorum Literatum Magistri, Salmanticae, Apud Nicolaum Josephum Villargordo, 1740.

Botelho de Moraes e Vasconcellos, Francisco, Satyrae Equitis Domini Francisci Botelho de Moraes et Vasconcellos, Academici Regii Hispanae Regalis Academiae ab semper Augusto Rege Hispaniarum Matriti erectae. Cum Notis et Argumentis Doctoris Domini Joannis Gonzalez de Dios, In Salamanticensi Academia Primarii Humaniorum Literatum Magistri, Salmanticae, Apud Nicolaum Josephum Villargordo, 1741.

Botelho de Moraes e Vasconcellos, Francisco, Satyrae Equitis Domini Francisci Botelho de Moraes et Vasconcellos, Academici Regii Hispanae Regalis Academiae ab semper Augusto Rege Hispaniarum Matriti erectae. Cum Notis et Argumentis Doctoris Domini Joannis Gonzalez de Dios, In Salamanticensi Academia Primarii Humaniorum Literatum Magistri, Salmanticae, Apud Nicolaum Josephum Villargordo, [Dez] 1742.

Botelho de Moraes e Vasconcellos, Francisco, Discurso Politico, Historico, e Critico, que em fórma de Carta escreveo a certo Amigo Francisco Botelho de Moraes e Vasconcellos, passando deste Reino para o de Hespanha, sobre alguns abusos, que notou em Portugal, Lisboa, Officina de Francisco Luiz Ameno Impressor da Congregação Cameraria da Santa Igreja de Lisboa, 1752.

Botelho de Moraes e Vasconcellos, Francisco, «Ode Saphyca», Jornal de Bellas Artes, ou Mnémosine Lusitana. Redacção Patriotica, 21, 1816, pp. 348-351.

Botelho de Moraes e Vasconcellos, Francisco, Historia das Covas de Salamanca do Cavalleiro Francisco Botelho de Moraes e Vasconcellos, Chronista Mór dos Estudantes, Trasgos e Feiticeiros, Abreviada e Traduzida por Joaquim Manoel d'Araujo Corrêa de Moraes, Professor d'Humanidades, Coimbra, Imprensa da Universidade, 1838.

Botelho de Moraes e Vasconcellos, Francisco, Historia de las Cuevas de Salamanca, introd. Fernando R. de la Flor, ed. Eugenio Cobo, Madrid, Tecnos, 1987.

Botelho de Moraes e Vasconcellos, Francisco, Satyrae..., ed. Christian Juan Porcar Bataller, Tesis Doctoral, Departamento de Filología Clássica, Universitat de València, 2013.

Braga, Theófilo, Historia da Literatura Portugueza. A Arcadia Lusitana, Porto, Livraria Chardon, 1899.

Carvalho, António Veloso de, Memoria das noticias que El Rey N. Sor. ordena se deam a academia Real da Estoria Portugueza, da Camera desta Va. da Torre de Mencorvo, e luguares de seu termo, Biblioteca Nacional de Portugal, Cod. 222, 11 de Junho de 1721, pp. 127-148.

Carreras y Bulbena, Joseph R., «Constitució y Actes conservades de la Academía Desconfiada, anomenada també Escola y Academía dels Desconfíats», en Boletín de la Real Academia de Buenas Letras de Barcelona, vol. 10, año 22 
(Académico 194), núm. 74, Barcelona, Casa Editorial Alberto Martín, Enero a Marzo 1922, pp. 225-277.

Castro, João Bautista de, «Francisco Botelho de Moraes e Vasconcellos», en Mappa de Portugal antigo e moderno, Lisboa, Off. de Francisco Luiz Ameno, 1763, vol. 2, pp. 309-310.

DRAE (Diccionario de la Lengua Castellana, en que se explica el verdadero sentido de las voces, su naturaleza, y calidad, con las phrases, o modo de hablar, los proverbios, o refranes, y outras cosas convenientes al uso de la lengua. Dedicado al rey nuestro señor Don Phelipe $V$ (que dios guarde) a cuyas reales expensas se hace esta obra. Compuesto por la Real Academia Española), Academicos Honorarios, vol. 6 [S-Z], Madrid, Real Academia Española: Por los Herederos de Francisco de el Hierro 1739, [p. 23].

Ferreira, Candida Florinda, «A Guerra da Sucessão no Distrito de Bragança (notícias inéditas)», sep. O Instituto, vol. 78, número 5, Lisboa, Tipografia Couto, 1929.

García Carraffa, Alberto y Arturo, Diccionario Heráldico y Genealógico de Apellidos Españoles y Americanos por..., vol. 16, Madrid, Nuevo Imprenta Radio/Litografia M. Casas, 1954.

Garcia Peres, Domingo, Catalogo Razonado Biográfico y Bibliográfico de los Autores Portugueses que escribieron en Castellano, ed. Ministerio de Fomento de España [com o beneplácito da Real Academia], Madrid, Imprenta del Colegio Nacional de Sordo-Mudos y de Ciegos, 1890.

Gasco, António Coelho, «Antiquário Discurso Dedicado ao III.mo e R.mo S.or D. Rodrigo da Cunha, Arceb.po de Braga, S.or Della, Primas das Hespanhas, e Elleito Metropolitano de Lisboa» [proferido entre 1627 y 1635], ed. António Cruz [«Um inédito de António Coelho Gasco sobre antiguidades de Trás-os-Montes»], Boletim da Biblioteca da Universidade de Coimbra, 1935, pp. 115-137.

GEPB (Grande Enciclopédia Portuguesa e Brasileira), «Vasconcelos (Francisco Botelho de Moraes e)», Lisboa e Rio de Janeiro, Editorial Enciclopédia Limitada, s/d, vol. 34, p. 284.

GL (Gazeta de Lisboa), Portugal, 10, Lisboa, 8 de Março de 1731, pp. 79-80.

GL (Gazeta de Lisboa), Portugal, 18, Lisboa, 3 de Maio de 1731, p. 144.

GL (Gazeta de Lisboa), Portugal, 3, Lisboa, 18 de Janeiro de 1746, p. 51.

GL (Gazeta de Lisboa), Portugal, 31, Lisboa, 2 de Agosto de 1746, p. 612.

GL (Gazeta de Lisboa), Portugal, 41, Lisboa, 13 de Outubro de 1757, pp. 335-336.

GL (Gazeta de Lisboa), Portugal Torre de Moncorvo, 13, Lisboa, 29 de Março de 1759, pp. 102-104.

Hill, Ruth, "Shapes of "Fable" and "History" in F. Botelho de Moraes e Vasconcelos's La historia de las cuevas de Salamanca (1734)», 17 th Annual Mid-A- 
merica Conference on Hispanic Literature, Lawrence, KS, September, 1994 $<$ www.academia.edu/attachments/.../download_file> [09/02/2015].

Hill, Ruth, «Sceptres and Sciences in the Spains: Four Humanists and the New Philosophy (ca. 1680-1740)», Hispanic Studies TRAC (Textual Research and Cristicism), 17, 2000 [Botello chapter four (pp. 191-244)].

José, Frei Pedro de Jesus Maria e, Cronica da Santa, e Real Provincia da Immaculada Conceição de Portugal da mais estreita e regular Observancia do Serafim Chagado S. Francisco, Lisboa, Officina de Miguel Manescal da Costa, 1760, vol. 2, 2. ${ }^{\text {a }}$ ed.

Lemos, Maximiano, «Vasconcellos (Francisco Botelho de Moraes e)», en Encyclopedia Portugueza Illustrada. Diccionario Universal, dir. Maximiano Lemos, Porto, Lemos e C ${ }^{a}$., Successor, s/d, vol. 11, p. 63.

Machado, Diogo Barbosa, «Francisco Botelho de Moraes, e Vasconcellos», en Bibliotheca Lusitana historica, critica e cronologica na qual se comprehende a noticia dos Authores Portuguezes, e das Obras, que compuserão desde o tempo da promulgação da Ley da Graça até o tempo prezente: Offerecida à Augusta Magestade de D. João V nosso senhor por [...], Lisboa Occidental, Officina de Ignacio Rodrigues, 1747, vol. 2, pp. 119-121.

Marcos de Dios, Ángel, «Índice de Portugueses en la Universidad de Salamanca», Brigantia revista de cultura, XXIII, 1/2, 2003, pp. 69-120.

Neves, Martinho Tomé das, «Poetae Vita», en Satyrae Equitis Domini Francisci Botelho de Moraes et Vasconcellos, Academici Regii Hispanae Regalis Academiae ab semper Augusto Rege Hispaniarum Matriti erectae. Cum Notis et Argumentis Doctoris Domini Joannis Gonzalez de Dios, In Salamanticensi Academia Primarii Humaniorum Literatum Magistri, Salmanticae, Apud Nicolaum Josephum Villargordo, [Dez] 1742, pp. 138-144.

Palau y Dulcet, Antonio, «Botello de Moraes y Vasconcellos (Francisco)», en Manual del librero hispano-americano; bibliografía general española e hispano-americana desde la invención de la imprenta hasta nuestros tiempos, con el valor comercial de los impresos descritos, Barcelona, Librería Palau, 1949, vol. 2, B, pp. 358-359, 2. ${ }^{a}$ ed.

Palma-Ferreira, João, Academias Literárias dos Séculos XVII e XVIII, Lisboa, Biblioteca Nacional, 1982.

Patriarcado de Lisboa, Os Cardeais Portugueses, <http://www.patriarcado-lisboa. pt/site/index.php?cont_=40\&tem $=161>[02 / 10 / 2014]$.

Pereira, Esteves e Guillerme Rodrigues, «Vasconcellos (Francisco Botelho de Moraes e)», en Portugal Diccionario Historico, Chorographico, Biographico, bibliographico, heraldico, Numismatico e Artistico, Lisboa, João Romano Torres e C. ${ }^{a}, 1915$, pp. 321-322. 
Porcar Bataller, Christian Juan, Satyrae del Ilustrado Portugués D. Francisco BoteIho de Moraes e Vasconcelos (1670-1747): Introducción, Edición Latina, Traducción y Comentario de Fuentes, Tesis Doctoral en Lenguas y Literaturas Clásicas, Departamento de Filología Clássica/Facultad de Filología, Tradución y Comunicación, Universitat de València, 2013.

R. de la Flor, Fernando, «Introducción», en Historia de las Cuevas de Salamanca, Madrid, Eugenio Cobos/Tecnos, 1987, pp. 9-42.

R. de la Flor, Fernando, «Nota sobre el caballero portugués Francisco Botello de Moraes. Un miembro de la R.A.E. y un iberista "avant la lettre" en la Salamanca de la pre-ilustración», en Palabras, norma, discurso. En memoria de Fernando Lázaro Carreter, Salamanca, Acta Salmanticensia/Estudios Filológicos, 2005, pp. 1017-1027.

RAE (Real Academia Española), Breve historia. Origen y fines, $<$ www.rae.es $>$ [s/d].

Riquer, Martín de, «Breve historia de la Real Academia de Buenas Letras de BarceIona», en Historia y labor de la Real Academia de Buenas Letras de Barcelona desde su fundacion en el siglo XVIII, Barcelona, Real Academia de Buenas Letras, Gráficas Marina, 1955, pp. 3-32.

Rivas Calvo, Emilio e Carlos d'Abreu, «A inspiração portuguesa de Diego de Torres Villarroel (1694-1770)», Praça Velha. Revista cultural da cidade da Guarda, 26, 2009, pp. 213-235.

Rodrigues, Maria Teresa Campos, «Rico-homem», en Dicionário de História de Portugal, ed. Joel Serrão, Porto, Livraria Figueirinhas, 1992, vol. V, p. 345.

Sá, José António de, «Descripção Económica da Torre de Moncorvo», en Memorias Economicas da Academia Real das Sciencias de Lisboa, Lisboa, 1791, vol. 3, pp. 253-290.

Santos, Maria Luísa Gil dos, O ciclo vivencial do Mosteiro de Nossa Senhora da Assunção de Tabosa, Dissertação de Mestrado em História Moderna, Faculdade de Letras, Universidade do Porto, 2000.

Seabra, Manuel Ferreira de e António Luís de Seabra, «Poesia (Artigo communicado). Ode Saphica», Jornal de Bellas Artes, ou Mnémosine Lusitana. Redacção Patriotica, 21, Lisboa, na Impressão Regia, 1816, pp. 348-351.

Silva, Inocêncio Francisco da, Dicionário Bibliográfico Português, vol. 2 (C-F), Lisboa, Imprensa Nacional, 1859, pp. 358-359.

Simón Díaz, José, «Botello de Moraes (Francisco)», en Bibliografía de la Literatura Hispánica, Madrid, Consejo Superior de Investigaciones Científicas/Instituto Miguel de Cervantes de Filología Hispánica, 1973, vol. 6, p. 638, 2. a ed.

Vasconcelos, Manuel António de, «Torre de Moncorvo», en Dicionário Geográfico, Arquivo Nacional da Torre do Tombo, vol. 37, número 75, 13 de Março de 1758, pp. 659-674. 
